\title{
Impact of the SCF signaling pathway on leukemia stem cell- mediated ATL initiation and progression in an HBZ transgenic mouse model
}

\author{
Wakako Kuribayashi ${ }^{1,2,3}$, Kazuya Takizawa ${ }^{1}$, Kenji Sugata ${ }^{4}$, Madoka Kuramitsu $^{1}$, \\ Haruka Momose ${ }^{1}$, Eita Sasaki ${ }^{1}$, Yuki Hiradate ${ }^{1}$, Keiko Furuhata ${ }^{1}$, Yoshihisa Asada ${ }^{3}$, \\ Atsushi Iwama, Masao Matsuoka4, Takuo Mizukamii,* and Isao Hamaguchi,** \\ ${ }^{1}$ Department of Safety Research on Blood and Biological Products, National Institute of Infectious Disease, Tokyo, Japan \\ ${ }^{2}$ Department of Cellular and Molecular Medicine, Graduate School of Medicine, Chiba University, Chiba, Japan \\ ${ }^{3}$ Faculty of Pharmaceutical Sciences, Tokyo University of Science, Chiba, Japan \\ ${ }^{4}$ Laboratory of Virus Control, Institute for Virus Research, Kyoto University, Kyoto, Japan \\ * These authors have contributed equally to this study as the corresponding authors
}

Correspondence to: Takuo Mizukami, email: tmiz@nih.go.jp

Keywords: ATL, HBZ, leukemia stem cells, cancer stem cell, SCF

Received: May 23, $2016 \quad$ Accepted: June 01, $2016 \quad$ Published: June 21, 2016

\section{ABSTRACT}

Adult T-cell leukemia (ATL) is a malignant disease caused by human T-lymphotropic virus type 1. In aggressive ATL, the response to chemotherapy is extremely poor. We hypothesized that this poor response is due to the existence of chemotherapy-resistant cells, such as leukemic stem cells. Previously, we successfully identified an ATL stem cell (ATLSC) candidate as the c-kit ${ }^{+} /$CD38-/CD71- cells in an ATL mouse model using Tax transgenic mice. Here, with a new ATL mouse model using HBZ-transgenic mice, we further discovered that the functional ATLSC candidate, which commonly expresses c-kit, is drug-resistant and has the ability to initiate tumors and reconstitute lymphomatous cells. We characterized the ATLSCs as c-kit ${ }^{+}$/ CD4-/CD8 ${ }^{-}$cells and found that they have a similar gene expression profile as $\mathrm{T}$ cell progenitors. Additionally, we found that AP-1 gene family members, including Junb, Jund, and Fosb, were up-regulated in the ATLSC fraction. The results of an in vitro assay showed that ATLSCs cultured with cytokines known to promote stem cell expansion, such as stem cell factor (SCF), showed highly proliferative activity and maintained their stem cell fraction. Inhibition of c-kit-SCF signaling with the neutralizing antibody ACK2 affected ATLSC self-renewal and proliferation. Experiments in SI/SId mice, which have a mutation in the membrane-bound c-kit ligand, found that ATL development was completely blocked in these mice. These results clearly suggest that the c-kit-SCF signal plays a key role in ATLSC self-renewal and in ATL initiation and disease progression.

\section{INTRODUCTION}

Adult T-cell leukemia (ATL) is a peripheral T cell leukemia caused by infection with human T-lymphotropic virus type 1 (HTLV-1) [1, 2]. HTLV-1 infection mainly occurs through breast-feeding, and after a long latency period, HTLV-1 infected cells finally develop into ATL cells [3]. Most infectious carriers never show any clinical signs, but approximately $3-5 \%$ of HTLV-1 carriers develop ATL [4]. Although combination chemotherapy has been promising in patients with indolent type ATL, the prognosis is much worse for patients with the most aggressive ATL type, with frequent resistance to or early relapse after intensive polychemotherapy $[5,6]$.

The existence of chemotherapy- and radiation therapy-resistant cancer stem cells (CSCs) [7], which are 
characterized by tumor initiating ability, self-renewal, and drug resistance and are a phenotypically and molecularly distinct rare population that can reproduce original tumor cell types in in vivo transplantation assays, has been hypthesized [8]. The CSC hypothesis is supported experimentally by findings from some hematological malignancies [9-13] and solid tumors [14, 15]. These findings provide strong evidence that CSCs might have a key role in cancer development and chemotherapy resistance.

Recent studies suggest that ATL cells are phenotypically [16, 17], functionally, and molecularly heterogeneous [18]. Indeed, using criteria that CSCs harbor a high dye efflux function associated with drug resistance $[19,20]$, we found a functional ATL stem cell (ATLSC) candidate in an ATL mouse model using Taxtransgenic (Tax-Tg) mice [21, 22]. El Haji et al. also reported a tumor initiating ability in ATL cells from a TaxTg ATL mouse model, suggesting that these cells could be a therapeutic target for ATL [23]. More recently, Nagai et al. reported that $\mathrm{T}$ memory stem cells are responsible for the hierarchical apex of ATL that can reproduce patient ATL types in recipient immunodeficient mice [24]. These data strengthen the idea that rare ATLSCs might play a key role in ATL development and progression. However, it is still unclear what common feature of ATLSCs could be used as a molecular therapy target and which HTLV1 factor and genetic pathway cause ATLSC development and regulation.

Here, we show strong evidence that ATLSCs exist in another mouse model of ATL using HBZ-transgenic mice (HBZ-Tg). Although HTLV-1 Tax transcripts are only detected in about $60 \%$ of ATL cases $[25,26]$, the HTLV-1 b-zip factor (HBZ) gene is expressed in all ATL cases, and HBZ induced ATL/lymphoma development in vivo [27]. We also report that a common surface marker of ATLSCs, c-kit, is a key regulator of ATL disease initiation and progression. Thus, our findings support the ATLSC hypothesis and indicate that c-kit-SCF (stem cell factor) signaling could be a therapeutic target for ATL.

\section{RESULTS}

\section{HBZ-expressing mouse ATL cells possess tumor initiating ability}

In this study, we used ATL cells (named Ht48) isolated from an HBZ-Tg mouse [27, 28]. To assess the tumor initiating and regeneration abilities of $\mathrm{Ht} 48$ cells in vivo, we transplanted $1 \times 10^{7} \mathrm{Ht} 48$ cells into the C57BL/6-Ly5.1 mouse (Ly5.1) strain whose cells can be distinguished from the donor cells by FACS (Figure 1A). As in the donor HBZ-Tg mouse, ATL-like lymphoma in the recipient mouse can be recognized as spleen, liver, and ovary hypertrophy (Figure 1B). All recipient Ly5.1 mice showed body weight loss (data not shown), hepatosplenomegaly, and died within 30 days posttransplantation. The spleen, liver, and ovary weights were significantly increased in the recipient mice compared with those in control mice (no transplant, NT) (Figure 1C). Massive tumor cell infiltration can be seen in the recipient mouse spleen and ovaries. The numbers of MNCs, including lymphoma cells in the peripheral blood (PB), spleen, ovaries, LNs, and thymus, were also significantly higher in recipient mice than in NT mice (Figure 1D).

To characterize the lymphoma cell phenotype in each of the infiltrated tissues, we performed FACS analyses of previously identified surface antigens observed in the HBZ-Tg mouse model. Ht48 cells were classified into CD4 single-positive (4SP), CD8 single-positive (8SP), and CD4/CD8 double-positive or -negative (DP and DN cells, respectively) cells. The majority of the donor Ht48 cells were 8SP, DP, or DN. A similar phenotype to that observed in donor Ht48 cells was also detected in the recipient spleen, $\mathrm{BM}, \mathrm{PB}$, ovaries, and liver but not in the recipient LNs or thymus (Figure 1E).

Another ATL cell phenotypes previously reported in the Tax-Tg mouse model of ATL [22], CD38 ${ }^{+}$and $\mathrm{CD}^{+} 1^{+}$, was also evaluated in this HBZ-Tg model. In the major ATL cell population, both $\mathrm{CD}^{+} 1^{+}$and $\mathrm{CD} 38^{+}$cells were detected in the recipient spleen, $\mathrm{PB}$, and $\mathrm{BM}$ but were not observed in the recipient ovaries, liver, $\mathrm{LN}$, or thymus (Figure 1F). By using two different phenotypic analyses of mouse ATL cells, both Ht48 cell phenotypes (CD38 ${ }^{+}$ and $\mathrm{CD}^{+}$) can be commonly detected in the recipient $\mathrm{PB}, \mathrm{BM}$, and spleen. We calculated the average number of Ht48 cells in each of the hematopoietic and lymphoid tissues (Figure 1G) and found that the spleen is the most efficient tissue for Ht48 proliferation.

HBZ expression in recipient mice was also detected by FACS analysis in splenic Ht48 cells (Figure $1 \mathrm{H}$ ), and it was high in the DP, 8SP, and 4SP subsets (Figure 1I). A similar observation was made in the histological spleen sections. The ATL cells can be seen in the spleen, BM (Figure 2A and 2B), ovaries, and liver (data not shown). $\mathrm{CD}^{+} \mathrm{T}$ cells can be observed in the spleen, BM, and ovaries (Figure $2 \mathrm{C}-2 \mathrm{~F}$ ). In the spleen, $\mathrm{CD}^{+}$cells were found in the $\mathrm{T}$ cell-rich region but not in the $\mathrm{B}$ cell-rich follicle (Figure 2G) and near the red pulp (Figure $2 \mathrm{H}$ ). To identify the splenic ATL cells, we investigated the HBZ expression in spleen sections using in situ hybridization. We found that some HBZ-expressing Ht48 cells can be seen in the splenic $\mathrm{CD}^{+}$cell-rich region (Figure 2I$2 \mathrm{~J})$. Together, these findings suggest that the spleen is the major site of ATL cell proliferation in vivo and that splenic ATL cells possess tumor initiating capacity, both phenotypically and functionally. 
A

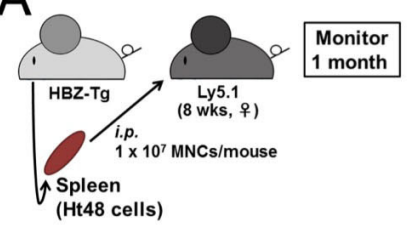

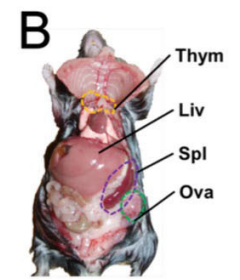

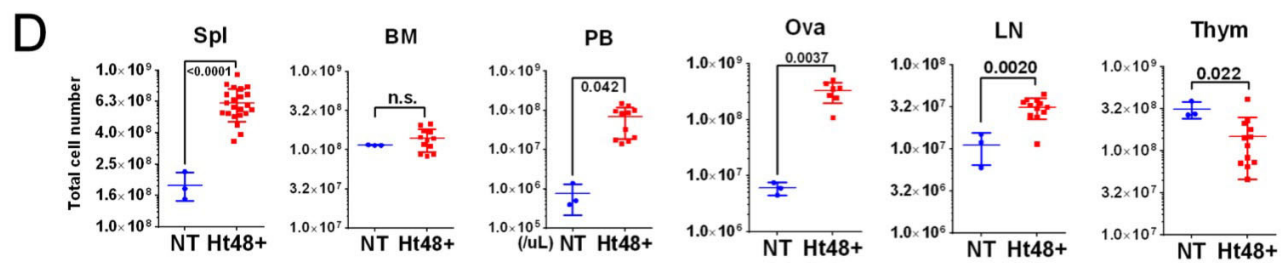
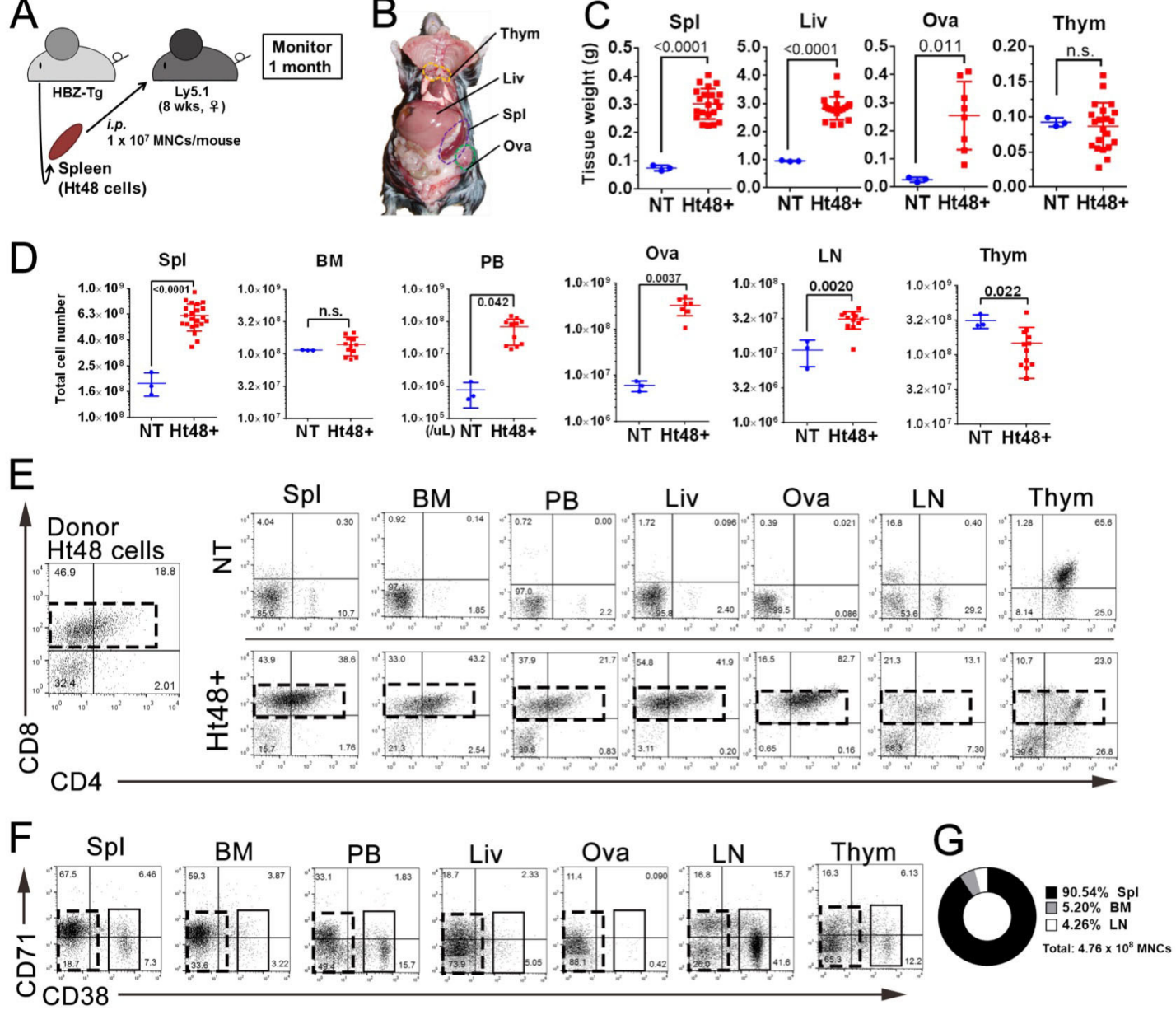

$\mathrm{H}$

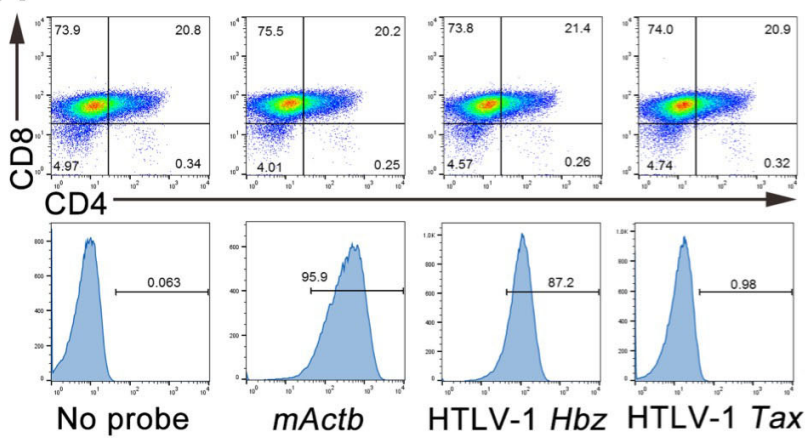

Hbz expressing cells

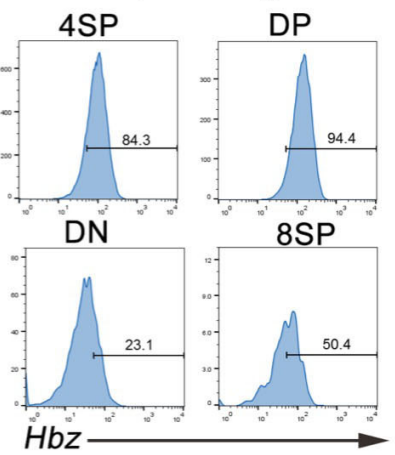

Figure 1: Assessment of the in vivo tumor initiating ability of HBZ-expressing mouse ATL cells (Ht48). A. Schematic representation of this experiment. We transplanted $1 \times 10^{7} \mathrm{Ht} 48$ cells derived from HBZ-Tg mouse splenic lymphomatous cells intraperitoneally (i.p.) into C57BL/6 (Ly5.1) mice. B. The gross anatomy of the recipient mouse 20 days after Ht48 cell transplantation. C.-D. Graphs depicting the weight C. and the cell number D. of each tissue after Ht48 cell transplantation. Each mouse is represented by a dot. Horizontal lines indicate the median. NT, no transplant; Ht48+, Ht48 cell transplantation; n.s., not significant. E.-F. Flow cytometric analyses to detect CD4 and CD8 expression $\mathbf{E}$. or CD71 and CD38 expression $\mathbf{F}$. in donor Ht48 cells from a recipient mouse. Representative flow cytometry plots of Ht48 cells before (left) and after transplantation (right) are shown. Boxes composed of red $\mathbf{E}$. and $\mathbf{F}$. or black F. dashed lines indicate the major Ht48 population. G. Graph depicting the percentage of the Ht48 cell distribution in each lymphohematopoietic tissue. H. A flow cytometric analysis was performed using a Primeflow ${ }^{\mathrm{TM}}$ assay to detect $\mathrm{HBZ}$ transcript in Ht48 cells. The Ht48 cells were separated by forward and side scatter (FSC and SSC, respectively) and by $\mathrm{CD}^{+}$and $\mathrm{CD} 8^{+}$for each gene transcript. Representative flow cytometry plots are shown, and the histograms depict the expression level of each gene in Ht 48 cells. No Probe, no probe hybridization; ACTB, mouse actin beta. I. Representative graphs of the HTLV-1 HBZ expression level in 8SP $\left(\mathrm{CD}^{-} \mathrm{CD} 8^{+}\right)$, DP $\left(\mathrm{CD}^{+} \mathrm{CD}^{+}\right)$, DN $\left(\mathrm{CD}^{-} \mathrm{CD}^{-}\right)$, or $4 \mathrm{SP}\left(\mathrm{CD}^{+} \mathrm{CD}^{-}\right) \mathrm{Ht} 48$ cells. Spl, spleen; BM, bone marrow (femur); PB, peripheral blood; Liv, liver; Ova, ovary; LN, lymph node (inguinal and axillary); Thym, thymus; NT, no transplantation. 


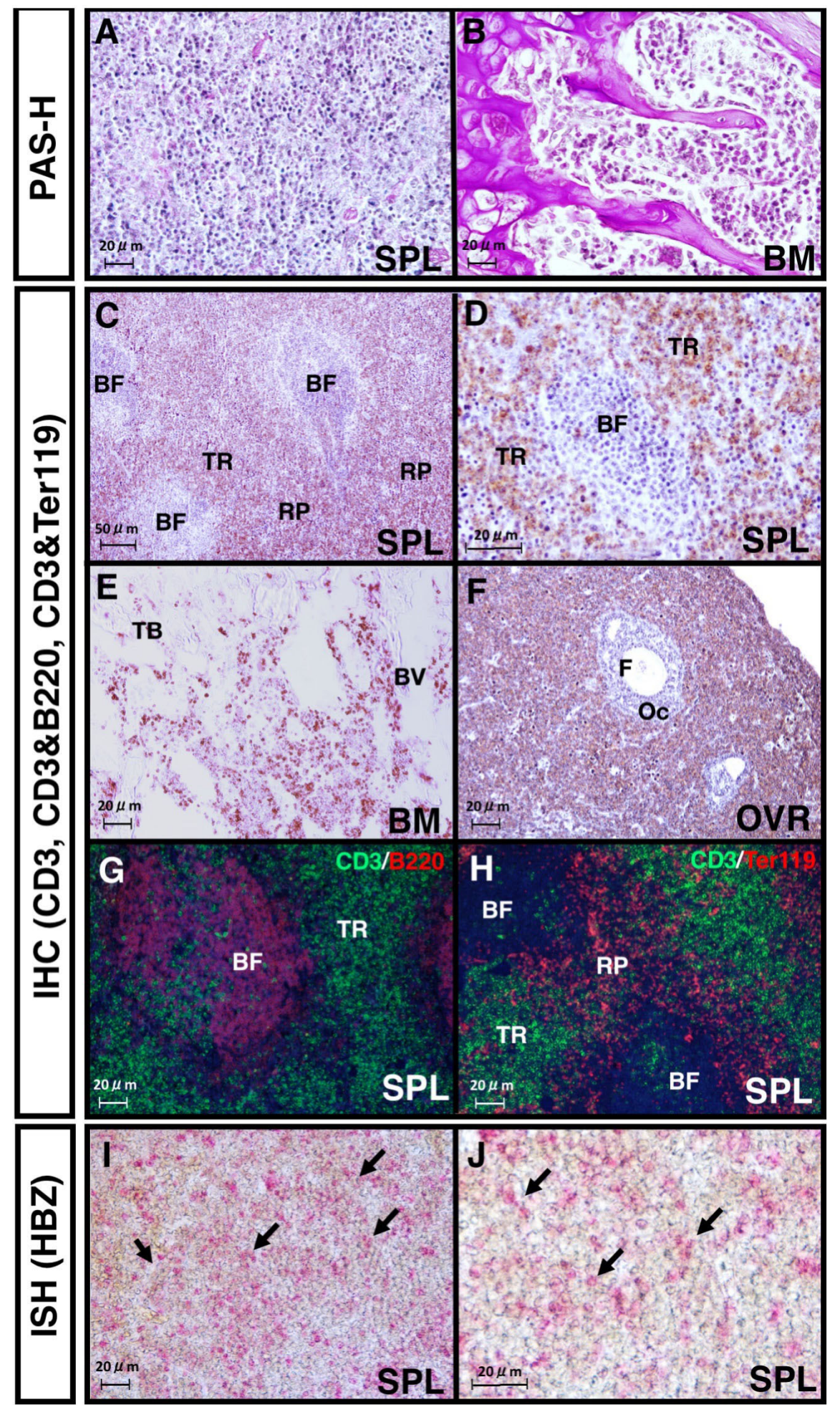

Figure 2: Histological analysis of lymphomas formed in the recipient spleens. A., B. Images of PAS- and hematoxylin- stained spleen A. or bone marrow (BM) sections B. 20 days after Ht48 cell transplantation. C. CD3-staining image of a section of a lymphoma that formed in a recipient spleen. BF: B follicle zone; TR: T cell-rich zone; RP: red pulp. D. High magnification image of the CD3 immunostaining of the spleen. E. Image of CD3 staining of a lymphoma-infiltrated recipient BM section. TB: trabecular bone zone; BV: blood vessel. F. Image of CD3 staining of a section of lymphoma-infiltrated recipient ovary. OC: oocyte; F: follicle G.-H. Images from immunofluorescence detections (IHC) of CD3 and B220 or CD3 and Ter119 in a section of a lymphoma that formed in a recipient spleen. I.-J. Images from an in situ hybridization (ISH) analysis of the HBZ transcript levels in a lymphoma that was formed in a recipient spleen. Red dots show HBZ transcript. Arrows indicate HBZ expression in the lymphoma-formed spleen. All images shown are representative of repeated observations. Scale bar: $100 \mu \mathrm{m}$. 


\section{Ht48 cells with tumor initiating ability act as stem cells in vivo}

To assess the capacity of $\mathrm{Ht} 48$ cells to act as stem cells and evaluate their tumor initiating ability, we designed a serial transplantation experiment. For each

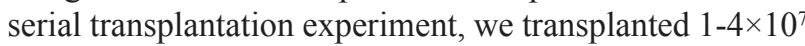
$\mathrm{Ht} 48$ cells isolated from former recipient lymphomas that developed in Ly5.1 mouse spleens into new recipient mice. We performed thirteen consecutive serial transplantation experiments (Figure 3A). The recipient mice died within 15-25 days in each of the transplantation experiments (Figure 3B). Consistent with the results described above, both the spleen tissue weight and total MNC number were significantly increased in recipient mice compared with those in NT mice (Figure 3C). We also performed FACS analyses to identify if $\mathrm{Ht} 48$ cells were capable of regenerating the original tumor phenotype in recipient mice. Similar Ht48 cell phenotypes (4SP, 8SP, DP, DN and $\mathrm{CD} 38^{+} / \mathrm{CD} 71^{+}$) were observed in the recipient mice following each serial transplantation experiment (Figure $3 \mathrm{D}$ and $3 \mathrm{E}$ ). These data suggest that functional ATLSCs with a self-renewal activity may exist among Ht48 cells.

\section{A subpopulation of high drug efflux capacity and c-kit expression cells exist in the $\mathrm{Ht} 48$ cell population}

To identify Ht48 cell ATLSC candidates, we performed a SP analysis that has been used previously to identify drug-resistant CSCs in various tumors4. Ht48 cells were divided into three SPs based on their Hoechst33342-low-fluorescence profile: the tip-SP fraction (Tip-SP; $0.029 \%$ ), the mid-SP population (MidSP; $0.87 \%$ ), and the major population (MP; 97.9\%) (Figure 4A). The ABCG transporter inhibitor, verapamil, effectively blocked the emergence of nearly all Tip-SP and most Mid-SP Ht 48 cells. We found that $>65 \%$ of the Tip-SP cells were ATLSC surface marker, c-kit ${ }^{+}$while $<10 \%$ of the non-SP fraction cells (MPs) were c-kit ${ }^{+}$ (Figure 4B-4C). Approximately $5 \%$ of the total $\mathrm{Ht} 48$ cell population were c-kit ${ }^{+}$, and of the c-kit ${ }^{+}$cells, most were 8SP, followed by DP, DN, and 4SP cells (Figure 4D). The c-kit ${ }^{+}$cells in the Tip-SP and Mid-SP fractions were mainly composed of DN cells ( $>70 \%$ ), whereas the c-kit MP cells were predominantly composed of $8 \mathrm{SP}$ and DP (Figure 4E). These results suggest that the $\mathrm{c}-\mathrm{kit}^{+}$ATLSC candidate with a high drug efflux capacity is enriched in the SP fractions and has a DN phenotype.

To assess the tumor repopulation ability of the c-kit ${ }^{+}$ $\mathrm{Ht} 48$ cells, we transplanted $5 \times 10^{3}{\mathrm{c}-k i t^{+}}^{+}$or c-kit ${ }^{-}$cells into Ly5.1 mice (Figure 4F). Whereas the mice that received a $5 \times 10^{3} \mathrm{c}-\mathrm{kit}^{-} \mathrm{Ht} 48$ cell transplantation lived for the entire observation period ( 80 days), the mice that received a $1 \times 10^{6}$ unfractionated $\mathrm{Ht} 48$ cell or $5 \times 10^{3} \mathrm{c}^{-\mathrm{kit}^{+}} \mathrm{Ht} 48$ cell transplantation died at similar rates during this period (Figure 4G). Because approximately $5 \%$ of $\mathrm{Ht} 48$ cells are $\mathrm{c}^{-\mathrm{kit}^{+}}$(Figure 4B), we speculated that $1 \times 10^{6}$ unfractionated $\mathrm{Ht} 48$ cells likely contain $5 \times 10^{4} \mathrm{c}-\mathrm{kit}^{+}$cells. Thus, we next intraperitoneally injected $5 \times 10^{1-3} \mathrm{c}-\mathrm{kit}^{+} \mathrm{Ht} 48$ cells or $1 \times 10^{6}$ Ht48 cells as a control into the Ly5.1 mice to assess the c-kit ${ }^{+}$cell tumor initiating ability (Figure $4 \mathrm{H}$ ). No mice died after receiving $5 \times 10^{1} \mathrm{c}-\mathrm{kit}^{+}$cells, but over half of the mice $(3 / 5)$ died after receiving $5 \times 10^{3}{\mathrm{c}-k i t^{+}}^{+}$cells. The survival rate of the recipient mice gradually decreased in a dose dependent manner (Figure 4I). A phenotypic analysis of post-transplantation Ht48 cells revealed that different numbers of transplanted $\mathrm{c}-\mathrm{kit}^{+}$cells all caused ATL development like transplanted bulk Ht48 cells (Figure $4 \mathrm{~J}$ and $4 \mathrm{~K})$. Together, these data clearly suggest that the population of c-kit ${ }^{+} \mathrm{Ht} 48$ cells may contain functional ATLSCs.

\section{c-kit ${ }^{+}$DN cells have ex vivo self-renewal capacity in vivo}

To assess the role of SCF-c-kit signaling in ATLSC self-renewal, we first cultured $1 \times 10^{4} \mathrm{Ht} 48$ cells with or without stem cell expansion-inducing cytokines (StemExpM: TPO, IL-6, Flt3, IL-3, and SCF) or a T cell expansion-inducing cytokine (TcellExpM: IL-2) (Figure 5A) for 6 days. The total Ht48 cell number was not changed among these groups within the 6-day culture (Figure 5B), but only the StemExpM increased the percentage of c-kit ${ }^{+} \mathrm{DN}$ (KDN) cells (Figure 5C and 5D). These data suggest that only StemExpM preserves ATLSC renewal, in vitro.

We next cultured $1 \times 10^{4} \mathrm{c}-\mathrm{kit}^{+} \mathrm{Ht} 48$ cells with or without StemExpM for 6 days. As expected, the total cell number increased significantly more when the c-kit ${ }^{+} \mathrm{Ht} 48$ cells were grown in StemExpM than in control medium (Figure 5E). Additionally, growth in the StemExpM induced more KDN cells than growth in control medium (Figure 5F). These data suggest that the ${\mathrm{c}-\mathrm{kit}^{+}}^{+}$ATLSCs were highly repopulated when the cells were grown in the StemExpM.

To understand which c-kit ${ }^{+}$cell type contributes to $\mathrm{Ht} 48$ stem cell repopulation, we sorted Ht48 cells and cultured the KDN, c-kit ${ }^{+}$DP (KDP), c-kit 4 SP (K4SP), and c-kit ${ }^{+} 8 \mathrm{SP}$ (K8SP) cells in StemExpM (Figure 5H). The KDN population proliferated more than 50 -fold in the StemExpM (Figure 5I and 5J). Together our findings suggest that the KDN population may contain ATLSCs, so we transplanted $5 \times 10^{3} \mathrm{KDN}$ Ht48 cells into Ly5.1 mice. As when $1 \times 10^{6} \mathrm{Ht} 48$ cells were transplanted, the mice that were transplanted with $5 \times 10^{3} \mathrm{KDN} \mathrm{Ht} 48$ cells died within 40 days (Figure $5 \mathrm{~K}$ ) and the original ATL lymphoma was recapitulated in recipient mouse spleens (Figure $5 \mathrm{~L}-5 \mathrm{~N}$ ). 
A

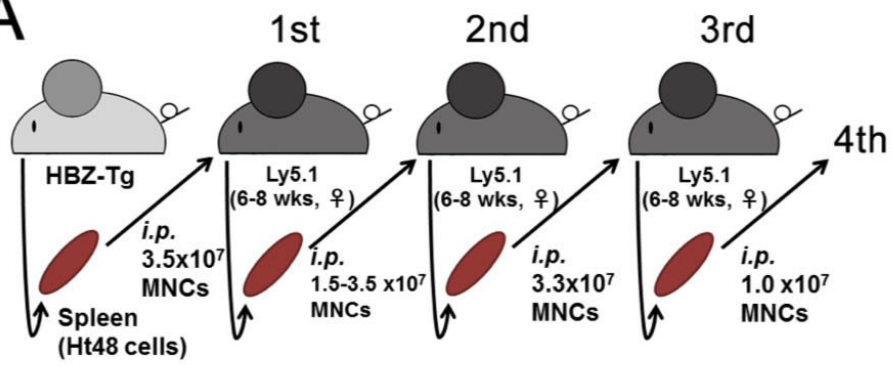

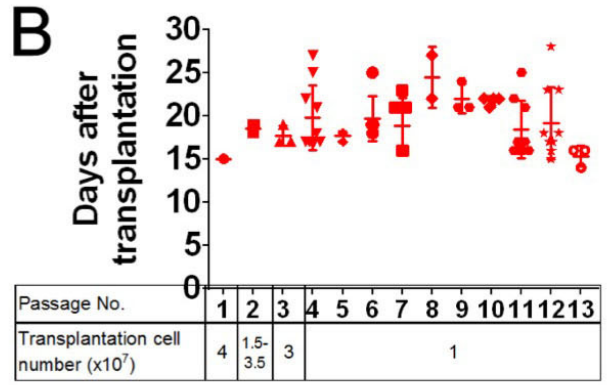

$\mathcal{C}$

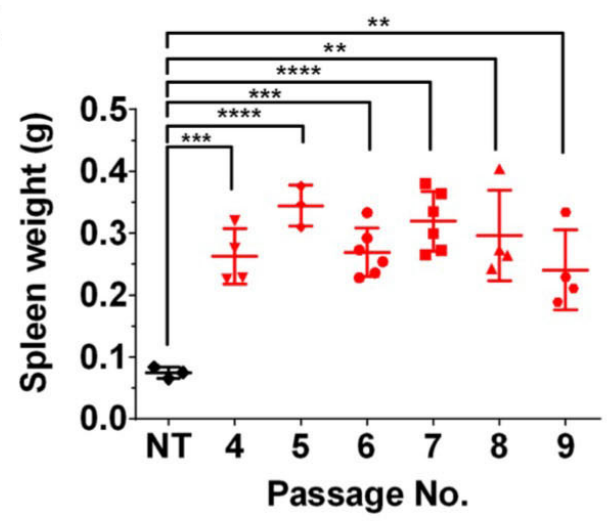

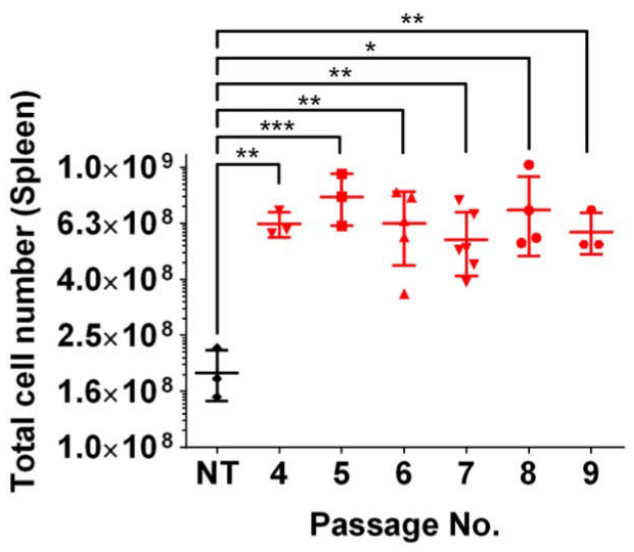

D

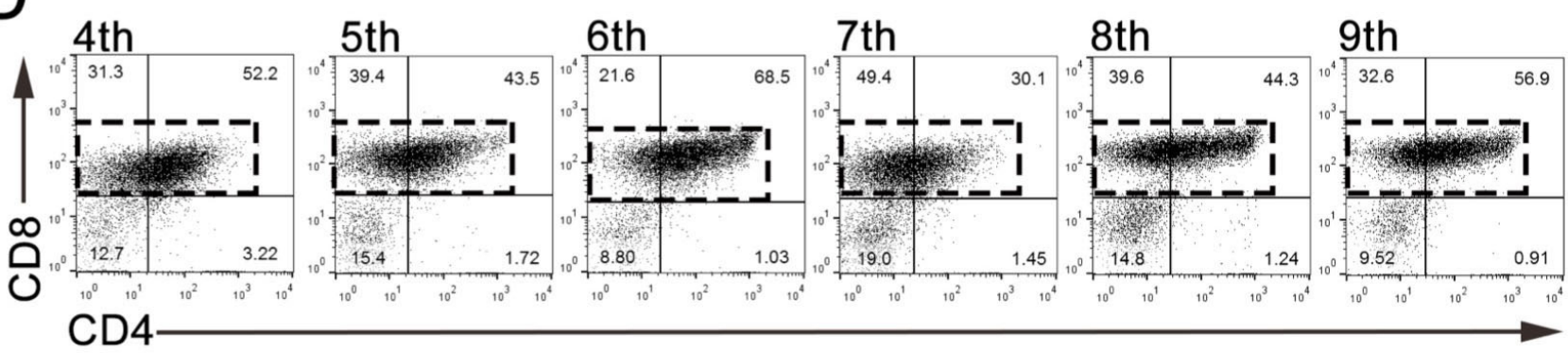

E

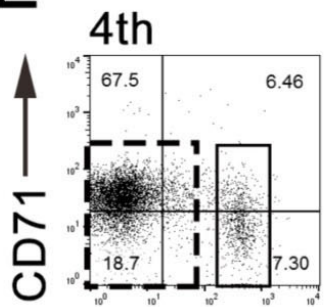

5th 6th

7th

8th
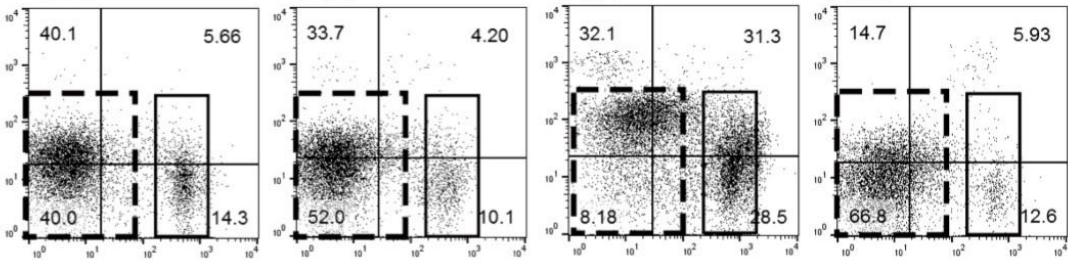

CD38

Figure 3: Evaluation of the in vivo ATLSC ability of $\mathbf{H t 4 8}$ cells by a serial transplantation assay. A. Schematic representation of the consecutive serial transplantation experiment. A total $1-4 \times 10^{7} \mathrm{Ht} 48$ cells were transplanted into C57BL/6 (Ly5.1) mice intraperitoneally (i.p) for the initial three consecutive serial transplantations, after which we transplanted $1 \times 10^{7} \mathrm{Ht} 48$ cells. wks, weeks B. Graph depicting the survival time after each of the 13 consecutive serial transplantations. Each mouse is represented by a dot. Horizontal lines indicate the median survival time. C. Graph depicting the spleen weight (left panel) and the number of MNCs in the spleen (right panel) at the sacrifice time points of passages 4-9 in the 13 consecutive serial transplantations experiment. Each mouse is represented by a dot. Horizontal lines indicate the median. NT: no transplantation control. $* * p<0.05$; $* * * p<0.005$; $* * * p<0.0005$. D.-E. Representative graphs from flow cytometric analyses to detect CD4 and CD8 expression D. or CD71 and CD38 expression E. in donor Ht48 cells from recipient mice after passages 4-9 D. or passages 4-8 E. in the 13 consecutive serial transplantations experiment. Boxes composed of red D. and E. or black E. dashed lines indicate the major Ht48 cell population. 


\section{Molecular signature of KDN cells and SP cells}

Here, we phenotypically and functionally identified an ATLSC candidate, both in vitro and in vivo. To clarify the ATLSC candidate molecular signature, we performed a DNA microarray analysis of the SP, KDN, and c-kit ${ }^{+} \mathrm{Ht} 48$
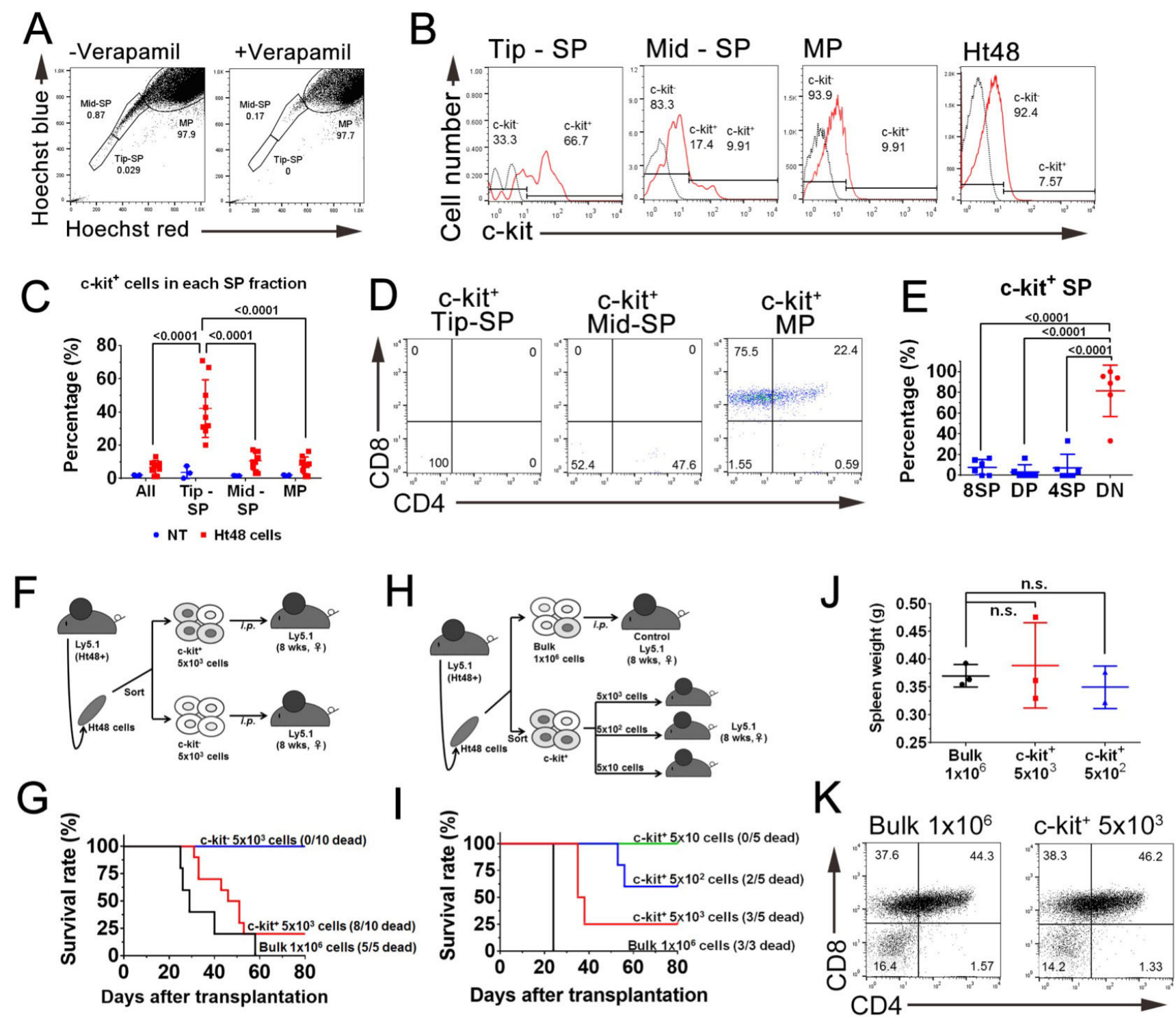

Figure 4: Evaluation of the dye efflux function in ATLSCs by a subpopulation analysis of Ht48 cells. A. Representative flow cytometric dot plot of the SP analysis of Ht48 cells. The dot plots show control Ht48 cells incubated in Hoechst33342 alone (left) or in the presence of $100 \mu \mathrm{M}$ verapamil (right). B. Representative histograms showing the proportion of c-kit ${ }^{+}$cells in the Tip-SP, MidSp, and MP fractions and in the unseparated Ht48 cells. C. Graph depicting the percentage of c-kit ${ }^{+}$cells in the SP and MP fractions. D. Representative dot plots from a flow cytometric analysis to detect CD4 and CD8 expression in the c-kit ${ }^{+}$SP donor Ht48 cells. E. Graph depicting the percentages of c-kit ${ }^{+}$SP cells that were 8SP, DP, 4SP, or DN. Each mouse is represented by a dot. F. Schematic representation

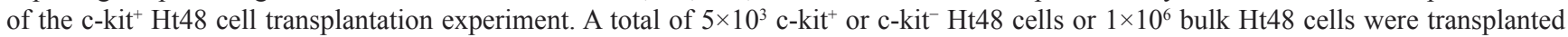
intraperitoneally into C57BL/6(Ly5.1) mice. Ht48+, Ht48 cell transplantation G. The overall survival of recipient mice transplanted with

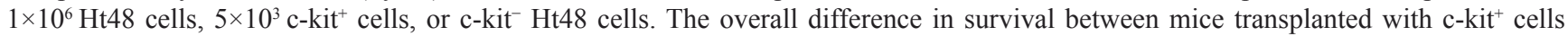
or c-kit ${ }^{-}$cells was statistically significant $(p<0.0001)$. H. Schematic representation of the follow-up c-kit ${ }^{+}$Ht48 cell transplantation

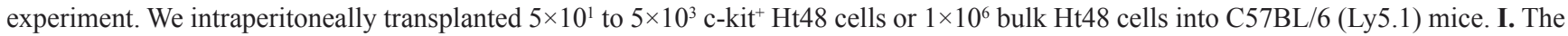
overall survival of recipient mice transplanted with $1 \times 10^{6}$ bulk Ht48 cells or with $5 \times 10$ to $5 \times 10^{3} \mathrm{c}-\mathrm{kit}^{+} \mathrm{Ht} 48$ cells. The overall difference in the survival between each of the groups was statistically significant $(p<0.0001)$. J. Graph depicting the weight of the spleen at the sacrifice time point after the transplantation experiment described above. Each mouse is represented by a dot. Horizontal lines indicate the median value. K. Representative dot plots from a flow cytometric analysis to detect CD8 and CD4 expression in unfractionated Ht48 cells and c-kit ${ }^{+}$ Ht48 cells after they were transplanted into recipient mice. 
A

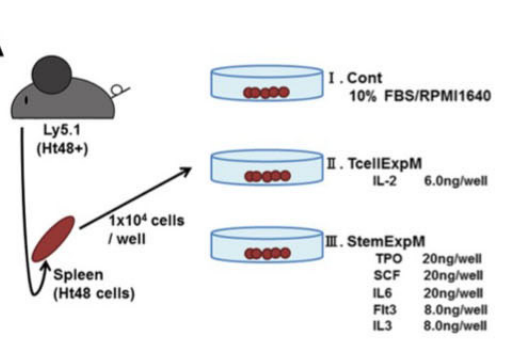

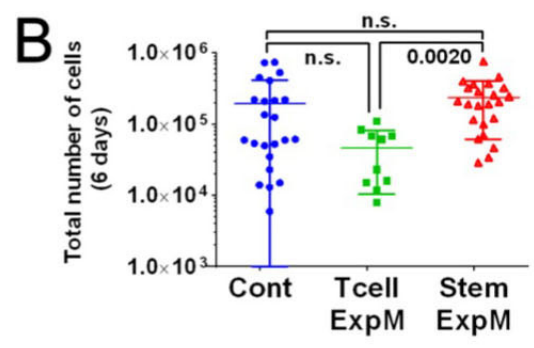

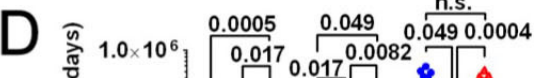

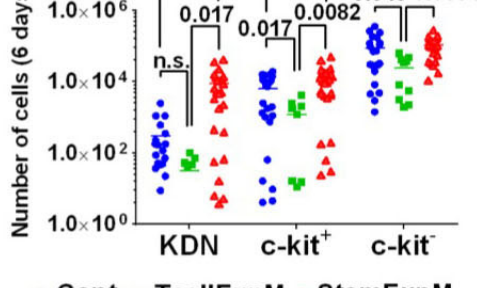

- Cont - TcellExpM $\Delta$ StemExpM
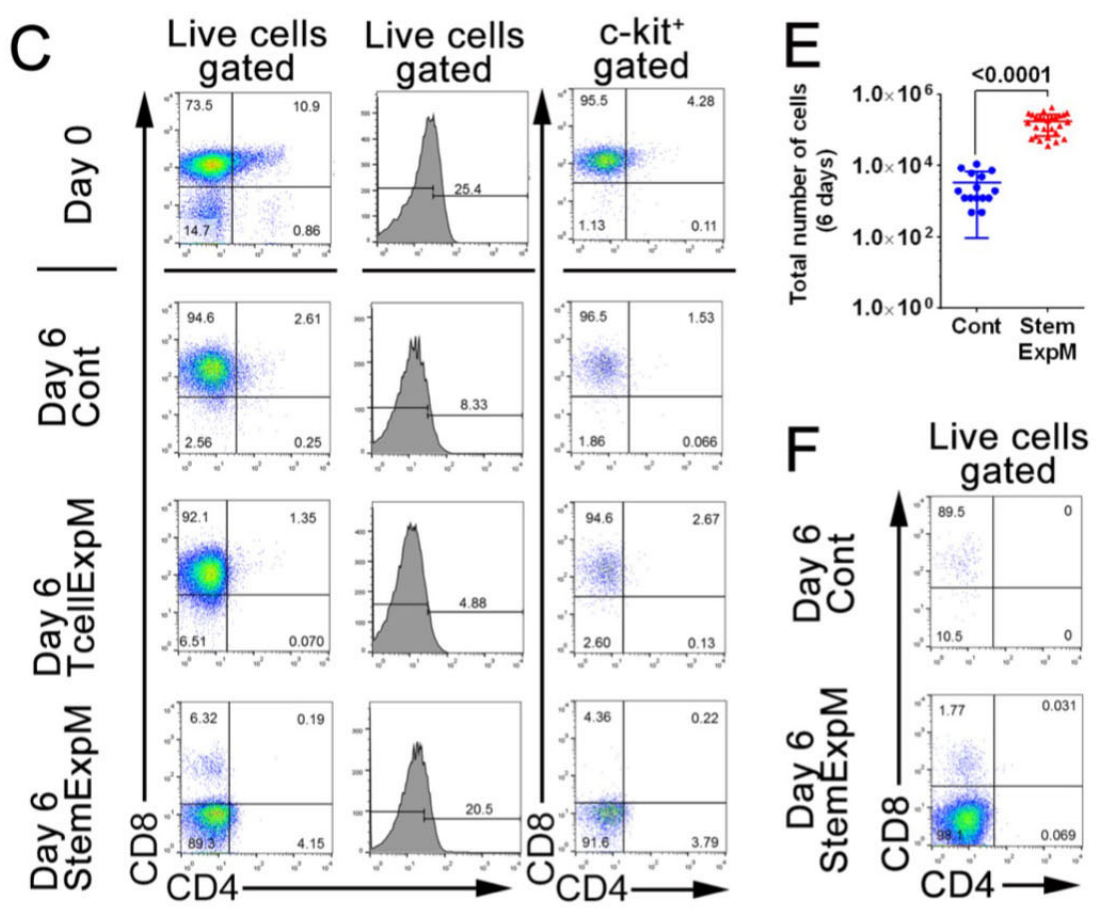

$G$
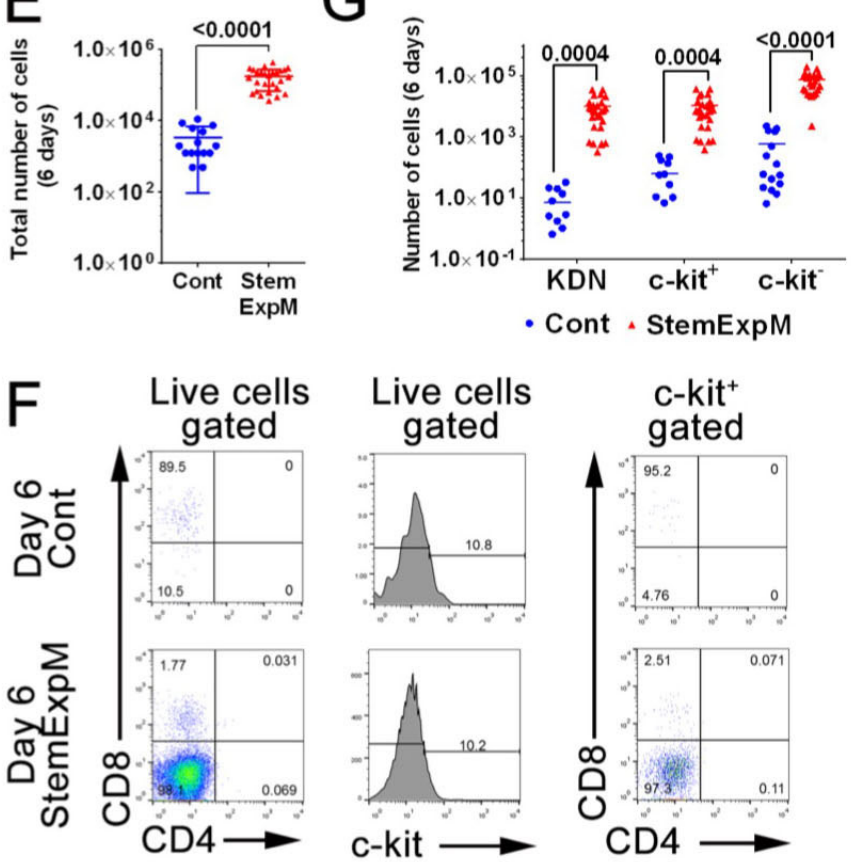

Live cells

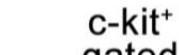

gated gated
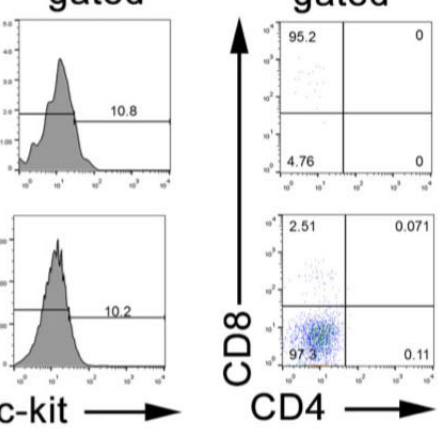

$\mathrm{H}$

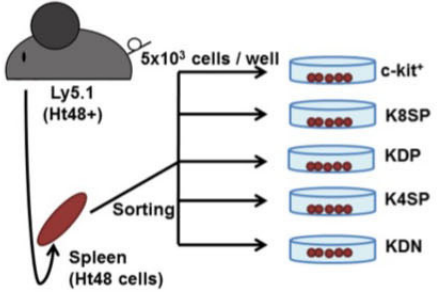

I

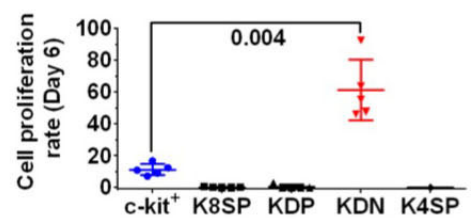

$\mathrm{K}$

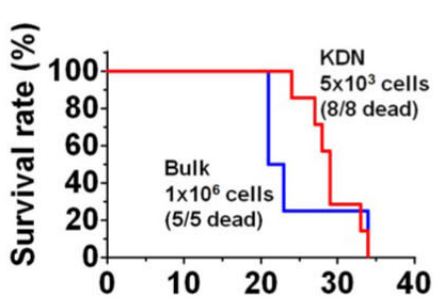

Days after transplantation
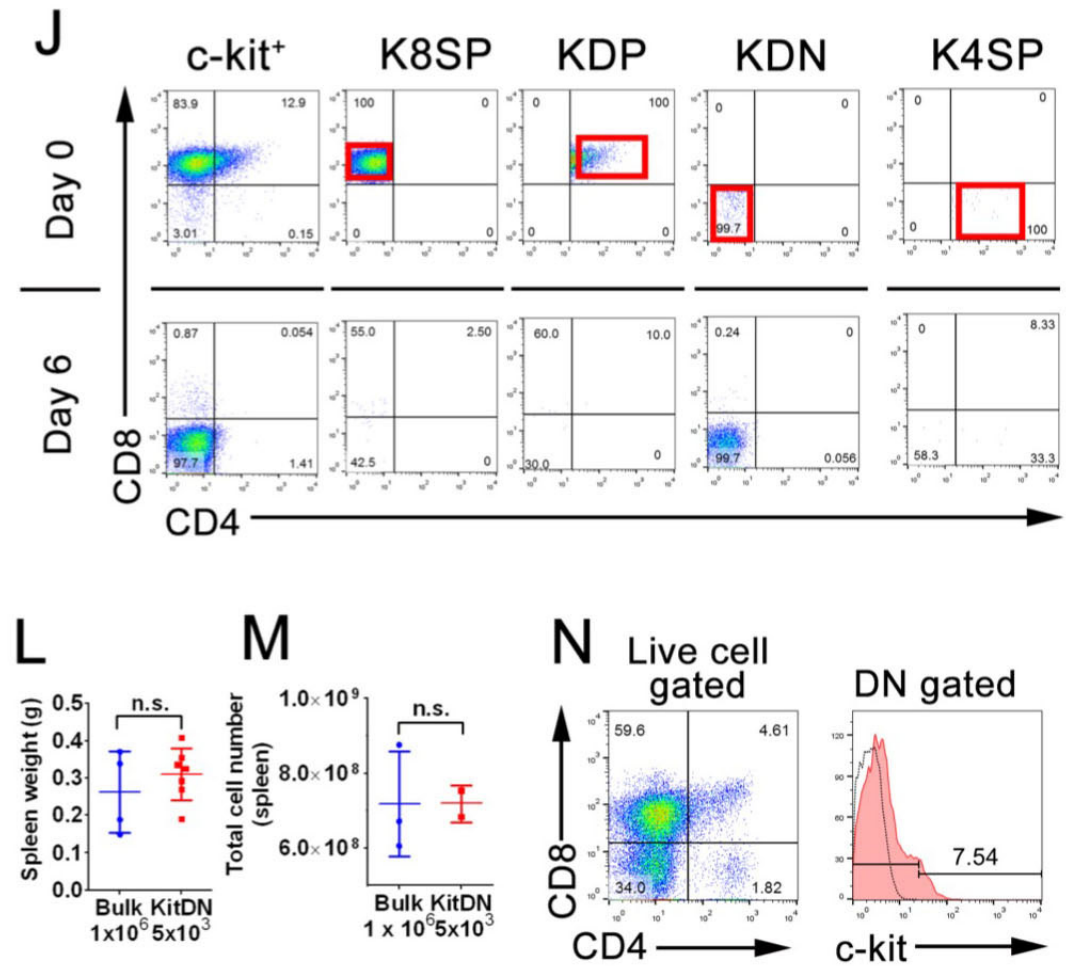
Figure 5: Effect of cytokine presence on ATLSC proliferation and differentiation. A. Schematic representation of the in vitro $\mathrm{Ht} 48$ cell proliferation assay. A total of $1 \times 10^{4} \mathrm{Ht} 48$ cells were cultured under multiple culture conditions for 6 days. Control media (Cont) consisted of base media (RPMI1640 with 10\% FBS) without cytokines. T cell expansion-inducing medium (TcellExpM) contained 6 ng/ well IL-2 in base media. The stem cell expansion-inducing medium (StemExpM) contained five cytokines (20 ng/well TPO, $20 \mathrm{ng} / \mathrm{well}$ SCF, $20 \mathrm{ng} /$ well IL-3, $8 \mathrm{ng}$ /well IL-6, and $8 \mathrm{ng} /$ well Flt3) in base media. B. Graph depicting the number of MNCs after a 6-day culture under the conditions described in (A). Each culture well is represented by a dot. Horizontal lines indicate the median number of MNCs. C. Representative dot plots from a flow cytometric analysis to detect CD4, CD8, and c-kit expression in donor Ht48 cells after a 6-day culture under the culture conditions described in (A). D. Graph depicting the number of c-kit ${ }^{+} \mathrm{CD} 4 / 8 \mathrm{DN}$ (KDN), c-kit ${ }^{+}$, and c-kit ${ }^{-} \mathrm{Ht} 48$ cells $^{-}$ after a 6-day culture under the conditions described in A. Each culture well is represented by a dot. Horizontal lines indicate the median number of cells. E. Graph depicting the number of MNCs after a 6-day culture of c-kit+ Ht48 cells under the conditions described in (A). Each culture well is represented by a dot. Horizontal lines indicate the median number of MNCs. F. Representative dot plots from a flow cytometric analysis to detect CD4, CD8, and c-kit expression in Ht48 cells after a 6-day culture of c-kit ${ }^{+} \mathrm{Ht} 48$ cells under the conditions described in (A). G. Graph depicting the number of KDN, c-kit ${ }^{+}$, and c-kit ${ }^{-} \mathrm{Ht} 48$ cells after a 6-day culture under the conditions described in (A). Each culture well is represented by a dot. Horizontal lines indicate the median number of cells. H. Schematic representation of the in vitro $\mathrm{Ht} 48$ cell proliferation assay. $\mathrm{Ht} 48$ cells were subdivided and sorted as a c-kit ${ }^{+} \mathrm{CD} 4^{-} \mathrm{CD} 8^{+}(\mathrm{K} 8 \mathrm{SP}), \mathrm{c}-\mathrm{kit}{ }^{+} \mathrm{CD} 4^{+} \mathrm{CD} 8^{+}(\mathrm{KDP})$,

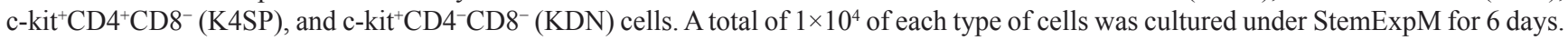
I. Graph depicting the fold increase change of each subset of $\mathrm{Ht} 48$ cells described in $(\mathrm{H})$ after a 6-day culture in StemExpM. Each culture well is represented by a dot. Horizontal lines indicate the median fold increase change. J. Representative dot plots of a flow cytometric analysis to detect CD4, CD8, and c-kit expression in each subset of donor Ht48 cells described in (H) after a 6-day culture in StemExpM. K. A transplantation experiment with KDN cells was performed. The overall survival of recipient mice after receiving a transplantation of $5 \times 10^{3} \mathrm{KDN}$ cells or $1 \times 10^{6}$ unfractionated Ht48 cells (Bulk) is shown. The overall difference in survival between these two groups is not statistically significant. L.-M. Graphs depicting the weight (L) and the cell number M of spleens after Ht48 cell or KDN transplantation. Each mouse is represented by a dot. Horizontal lines indicate the median. Ht48+, Ht48 cell transplantation; KDN, KDN transplantation; n.s., not significant. N. A representative dot plot from a flow cytometric analysis to detect CD4, CD8, and c-kit expression in donor Ht48 cells after transplantation of KDN.

cell subsets as compared with normal KDN. Expression data for 28,305 genes were acquired, and the resulting heat-map shows partitioning of five samples and the 15,882 genes. A hierarchical clustering analysis clearly shows that there are two distinct $\mathrm{Ht} 48$ cell populations; the KDN and SP cells are different from the c-kit ${ }^{+} \mathrm{Ht} 48$ cells and unfractionated Ht48 cells (Figure 6A). A similar clustering result was obtained in the immune regulatory genes (Supplemental Figure 1) and thymic early T-cell precursor (ETP) upregulated genes (Figure 6B). Among ETP gene set, we found HTLV-1 infection inducing gene, Nfe2 and Id 2 upregulation both in the SP and KDN cells. Thus, we next analyzed the expression pattern of HTLV1 and ATL related genes [29-34] in our mouse model. A similar clustering result was obtained in the ATL-related genes (Supplemental Figure 2). Among the 250 ATLrelated genes, 43 genes, including, AP-1 family genes, Fos and Jun, were up regulated both in Ht48 SP cells and KDN cells (Figure 6C). We next analyzed the AP-1 gene family member expression patterns in our mouse model and found Jun, Junb, and Jund were upregulated in Ht48 SP cells (Figure 6D). We used q-PCR to confirm the gene expression levels of randomly selected (Hlf, Tiel) or AP-1 family genes that are differentially expressed in KDN cells. Whereas the HBZ expression level was not changed between the Ht48 cells and the ATLSC candidates (Figure 6D), the expression levels of Hlf, Tie1, Junb, Jund, and Fosb were upregulated in ATLSC candidates (Figure 6E6G). Then, we used a Primeflow assay, which can detect mRNA expression, and found mActb-. HBZ-, Hlf-, Tiel-, JunB-, JunD-, expressing cells were detected among the KDN cells (Figure 6G). Finally, we listed the top 330 genes highly expressed in SP cells (Supplemental Table 3).

\section{c-kit-SCF signaling plays a key role in ATL progression in vivo}

To confirm the role of c-kit-SCF signaling in ATLSC self-renewal, we blocked the c-kit signaling in vitro by neutralizing the c-kit receptor with the neutralizing antibody ACK2. Although StemExpM stimulates c-kit ${ }^{+}$ cell proliferation, ACK2 effectively blocked the c-kit ${ }^{+}$ cell proliferation as did StemExpM lacking SCF (Figure 7A). SCF neutralization in vitro also reduced ATLSC self-renewal (Figure 7B). The KDN Ht48 cell number dramatically reduced in StemExpM with ACK2 or lacking SCF.

To clarify the role of c-kit-SCF signaling in vivo, we transplanted $1 \times 10^{6} \mathrm{Ht} 48$ cells into Sl/Sld mice. These mice lack membrane-bound SCF, which is essential for hematopoietic stem cell proliferation and differentiation [35] (Figure 7C). Because most Sl/Sld mice die by 15 weeks old owing to severe anemia, we used 8 weeks old Sl/Sld mice and evaluated an engraftment of ATL cells 20-30 days after transplantation. No ATL development was detected in the recipient $\mathrm{Sl} / \mathrm{Sld}$ mice. The spleen weight and $\mathrm{MNC}$ number in recipient $\mathrm{Sl} / \mathrm{Sld}$ mice were lower than those in recipient Ly5.1 mice (Figure 7D). ATL cells, including 4SP, 8SP, and DP, were not observed in the S1/Sld mouse spleens and thymuses (Figure 7E). These data suggest that c-kit-SCF signaling is essential for ATL development and progression in vivo. 
A

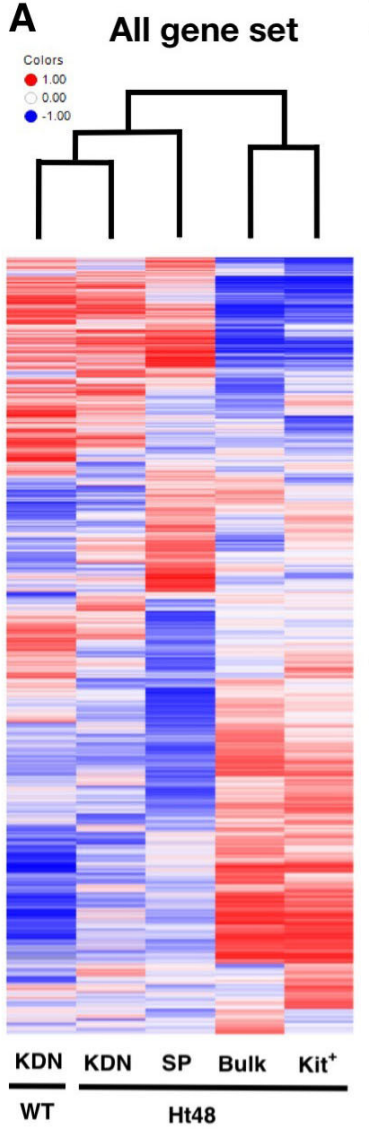

$B$ ETP gene set
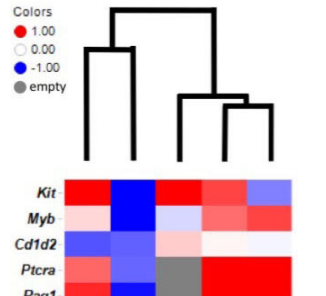

.

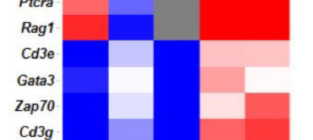

Zap 70
Cd $3 g$

$\mathrm{Cd} 3 \mathrm{~d}$

Bc/11b
Left

Cd1d1
Lck

Lck
Notch1

Tcf12
Notch 3

Cd4

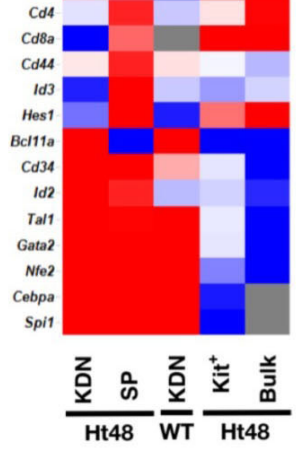

C ATL related gene set

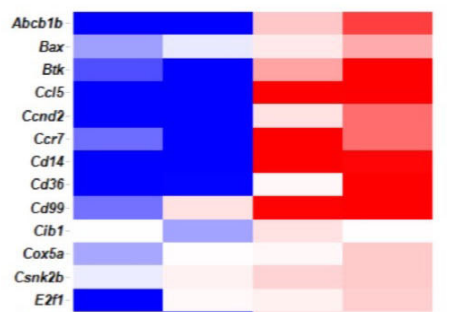

\section{AP-1 network}
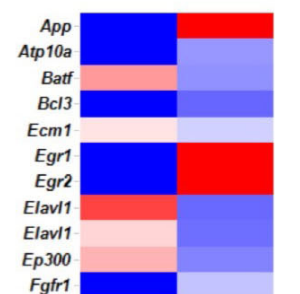

Fgfr1

Gstm1

Hmox1

Hmox1

Jun

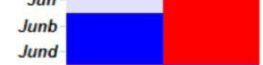

Ldb1

Msx1

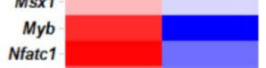

Nfatc1
Nfatc1

Nos?

Nos2
Nr3c1
Nr3c1

Nr3c1

Nr4a2
Ppara

Relb

Retb

Relb

Sic20a1
Sstr5

St8sia4

Vim
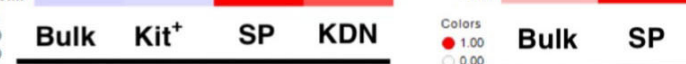

$\underset{0.00}{\bullet} \times 1.00$ Bulk SP

Ht48

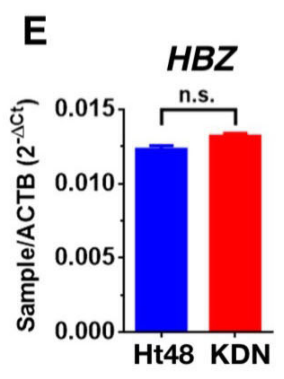

G

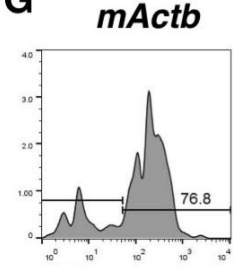

F

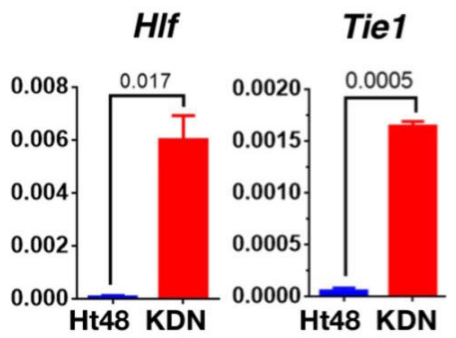

G
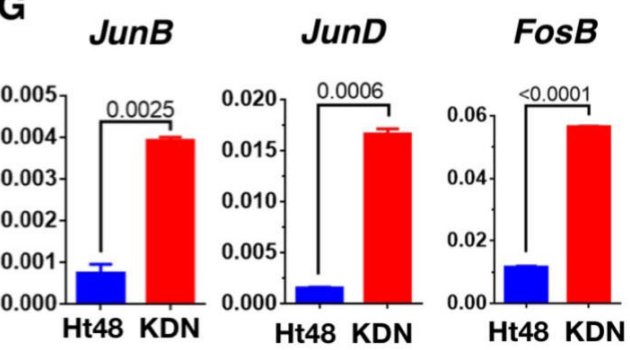

HBZ

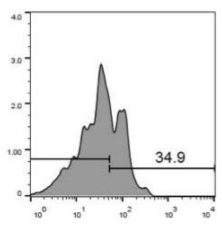

Hlf

Tie1

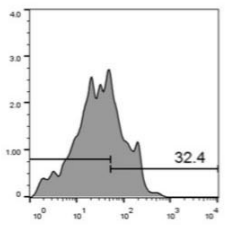

JunB

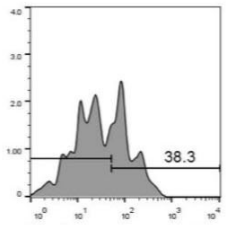

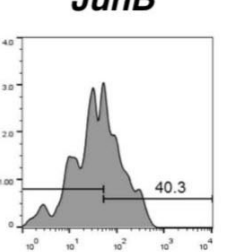

JunD

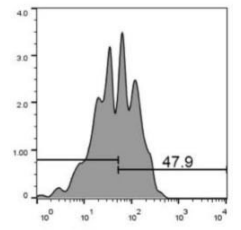

Figure 6: Global gene expression profile of $\mathbf{H t 4 8}$ cells. Ht48 cells were subdivided into c-kit ${ }^{+}$cells, c-kit ${ }^{+} \mathrm{CD} 4 / 8 \mathrm{DN}(\mathrm{KDN})$ cells, SP cells, and normal WT counterpart c-kit ${ }^{+} \mathrm{CD} 4 / 8 \mathrm{DN}(\mathrm{WT}-\mathrm{KDN})$ cells. A. Unsupervised hierarchal clustering of 15,882 gene expression profiles obtained from each fraction using an Agilent DNA microarray system. B. Hierarchal clustering of gene expression profiles obtained from each fraction using the ETP gene list. C. Gene expression profiles obtained from each fraction using the HTLV-1 infection and ATLrelated gene list. D. Gene expression profiles obtained from each fraction using the AP-1 family gene network gene list. E.-G. A q-PCR analysis of differentially-expressed genes between unfractionated Ht48 cells (Bulk) and KDN cells. The expression levels of HTLV-1 HBZ E., randomly selected genes from upregulated genes in SP cells, Hlf, Tie1, F., and members of the AP-1 gene family including, Junb, Jund, Fosb in KDN G.. H. A flow cytometric analysis was performed using a Primeflow ${ }^{\mathrm{TM}}$ assay to detect q-PCR confirmed genes including, mActb, HBZ, Hlf, Tie1, Junb, and Jund in KDN cells. The Ht48 cells were separated by forward and side scatter (FSC and SSC, respectively) and by $\mathrm{CD}^{+}$and $\mathrm{CD} 8^{+}$for each gene transcript. Representative flow cytometry plots are shown, and the histograms depict the expression level of each gene in KDN cells. 


\section{DISCUSSION}

ATL is a malignant disease of mature T cells caused by HTLV-1 infection [1.2] that has a poor prognosis owing to the resulting severe immune-suppression and its intrinsic resistance to chemotherapy [36]. Recently, the
CSC hypothesis $[37,38]$ was proposed to explain the cause of ATL chemotherapy resistance [39]. Here, we found that ATLSC candidates display a c-kit ${ }^{+} / \mathrm{CD}^{-} / \mathrm{CD}^{-}$phenotype in the HBZ-Tg ATL mouse model. ATLSCs have distinct phenotypic, genetic, and functional properties than the majority of ATL cells and can reconstitute the original ATL in recipient mice many times over and maintain a

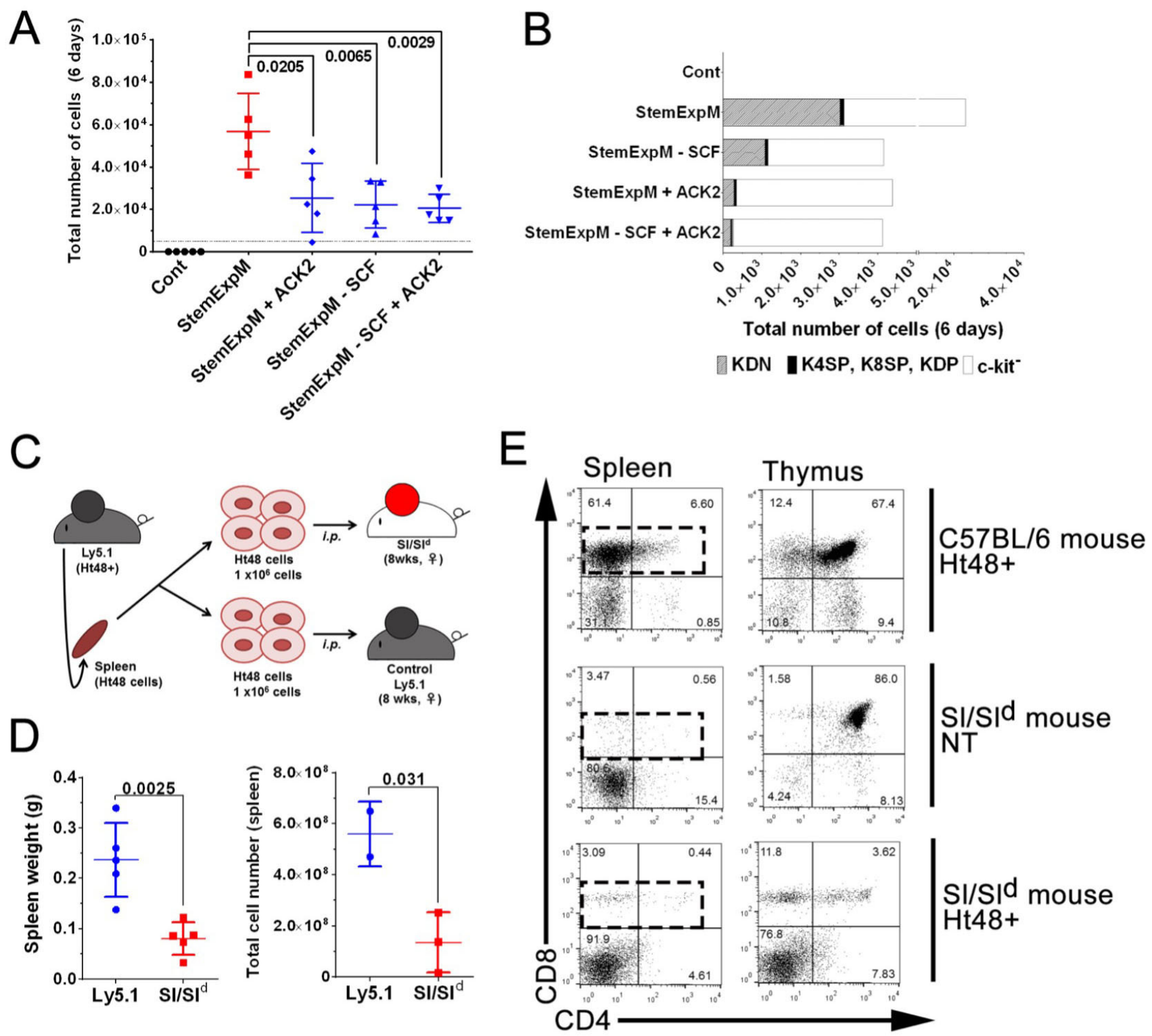

Figure 7: Effects of blocking SCF-c-kit signaling either in vitro or in vivo on ATLSC proliferation. A. A total of $1 \times 10^{4}$ Ht48 cells were cultured under a variety of culture conditions for 6 days. StemExpM: Stem cell expansion-inducing medium; StemExpM +ACK2: Stem cell expansion-inducing medium plus the c-kit-neutralizing antibody ACK-2; StemExpM -SCF: Stem cell expansioninducing medium lacking SCF; StemExpM -SCF+ACK2: Stem cell expansion-inducing medium lacking SCF plus the c-kit-neutralizing antibody ACK-2. Graph depicting the number of MNCs in each culture condition. Each culture well is represented by a dot. Horizontal lines indicate the median number of MNCs. B. Percentage of KDN, c-kit ${ }^{+}$cells excluding the $\mathrm{CD}^{-} \mathrm{CD} 8^{-}$cells, and c-kit ${ }^{-} \mathrm{Ht} 48$ cells after a 6-day culture under the conditions described in A.. C. Schematic representation of an in vivo transplantation experiment using S1/Sld mice, which lack membrane-bound SCF. A total of $1 \times 10^{6} \mathrm{Ht} 48$ cells were transplanted intraperitoneally into control C57BL/6(Ly5.1) mice or Sl/ Sld mice. D. Graph depicting the tissue weight (left panel) and the cell number (right panel) of each tissue after Ht48 cell transplantation. Each mouse is represented by a dot. Horizontal lines indicate the median value. E. Representative dot plots of a flow cytometric analysis to detect CD4 and CD8 expression in donor Ht48 cells in the spleen of recipient mice. 
SP phenotype with a high drug efflux capacity [39]. These findings, together with our previous data, suggest that both Tax and HBZ might have the ability to induce leukemia stem cell properties in mouse $\mathrm{T}$ cells by inducing a high drug efflux ability.

The global gene expression study results indicate that many HBZ-interacting genes, such as the AP-1 family genes including C-Jun, Junb [40], and Jund [41], which are associated with leukemogenesis, are highly upregulated in ATLSCs. AP-1 family genes $c$-fos, c-Jun, $A t f$, and $J d p$ were also regulated by HTLV-1 Tax [42, $43]$, and they are involved in many cellular processes, such as proliferation, differentiation, and apoptosis. Interestingly, AP-1 and downstream microRNA-21 (miR-21) were upregulated in highly chemoresistant SP cells in several cell lines, and AP-1 inhibition reversed the chemoresistance and colony forming ability of SP cells [44]. Additionally, downregulation of junB/AP-1 transcription factor recapitulates the clinical aspects of CML [45] and AML [46] and JunB deficiency leads to a CSC-mediated myloproliferative disorder [47, 48]. Our microarray data show that Junb and Jund were also upregulated in the ATLSC fraction, and this finding was confirmed with the results from both q-PCR and FACS assays. Thus, both HBZ and Tax may induce or disrupt the AP-1 gene expression network and finally induce CSC properties, including the SP cell phenotype, in vivo. Further analyses are needed to confirm and reveal the molecular network underlining ATLSC development via the AP-1 gene family.

ATLSCs from both Tax- and HBZ-driven ATL commonly expressed c-kit, and the c-kit-SCF signaling pathway plays a major role in CSC-mediated ATL progression. Therefore, the SCF-c-kit signaling pathway is a possible therapeutic target in ATL. In mice, c-kit is a key regulator of hematopoietic stem and progenitor cells as well as testicular and intestinal cells [49]. Inhibition of c-kit kinase activity has been found several cancers. In AML, approximately $85 \%$ of AML cells express c-kit [50], and SCF combined with IL-3 stimulates massive AML cell proliferation [51]. Despite our previously published findings, it remained unknown if most ATL cells express c-kit. A distinct subset of self-renewing human memory $\mathrm{CD}^{+} \mathrm{T}$ cells with high dye efflux properties that expressed c-kit similarly to the Ht48 cells in our model has been reported [52]. Recent clinical studies also highlight the existence of ATLSCs in the ATL patient T memory stem cell fraction [53]. It is still unknown if $\mathrm{T}$ memory stem cells in ATL require SCF-c-kit signaling, and further functional studies are needed to determine if c-kit ${ }^{+}$cells also possess CSC properties in human ATL cases.

When we compared ATLSCs with normal c-kit ${ }^{+} \mathrm{CD} 4 / 8 \mathrm{DN}$ cell counterparts in a DNA microarray analysis, we found that each fraction showed a similar gene expression pattern suggesting that ATLSCs are of stem/progenitor cell origin or were reprogrammed into immature cell types by HTLV-1 infection.

In the thymus, immature $\mathrm{T}$ cell progenitors, DN1 cells [53], which express high levels of c-kit contain the most immature T lineage progenitors (ETPs) [54]. ETPs are derived from human stem cells but are non-renewing progenitors that have retained a limited multi-lineage differentiation potential. Oncogenically transformed ETPs might be one cause of recurrent leukemia, and they respond poorly to chemotherapy in $\mathrm{T}$ cell acute lymphoblastic leukemia [55]. In our analysis, the ETP gene set was also reclassified in HBZ-Tg ATL cells (Figure $6 \mathrm{~B})$ as well as in the global and immune gene sets. These data suggest that ATLSCs might acquire ETP properties or may maintain ETP properties during HTLV-1 infection. Because HTLV-1 infection occurs via breast feeding, and ETPs arise from the BM and are thought to migrate to the thymus during embryonic and postnatal development, ETPs may be a possible HTLV-1 infection target and long latency target for ATLSCs.

Recent studies suggest that human CD4/8DN cells may act as a reservoir of persistent of HIV-1 [56] and are associated with HIV-1 seroconversion [57]. Interestingly, CD4/8DN T cells still persist throughout highly active antiretroviral therapy suggesting that CD4/8DN T cells may affect drug resistance [58]. In addition, CD4/8DN T cells may play a variety of roles in the immune system, such as immune response, autoimmunity, immune tolerance in transplantation, and antitumor activity [59]. These data suggest that ATLSCs may play various roles in ATL development.

Although most of HBZ- expressing ATL cells (Ht48 cells) migrate into spleen like other T-ALL model [60], we found that HBZ-expressing ATL cells migrate and infiltrate into the ovaries (Figures 1 and 2). In nonHodgkin lymphoma, although 7-25\% of lymphoma cells infiltrate the ovaries [61], lymphomas arising primarily in extra-nodal sites (pENL) are extremely rare. Some pENL are associated with an underlying immunodeficiency syndrome, such as HIV/AIDS, or with an infection, such as Epstein-Barr virus, HTLV-1, human herpesvirus-8, or hepatitis $\mathrm{C}[62]$.

Most lymphoma cells are B cells, although some $\mathrm{T}$ cell and natural killer cell lymphomas were reported in the female genital tract [63]. In ATL, there are only a few reports that ATL cells infiltrate into the ovaries; many studies did not examine the ovarian involvement. Interestingly, an HTLV-1-inducible gene, TSCL1, promotes ovarian infiltration by an ATL cell line in the NOG mouse model [64]. Additionally, ATL-derived factor (ADF) has been detected in the human ovary throughout the menstrual cycle with high production levels during pregnancy [65]. ADF induces IL-2Ra in HTLV-1-infected cells [66] and promotes the proliferation of HTLV-1infected cells. Because SCF is also produced in the ovaries [67] we speculate that both ADF and SCF might act as chemoattractive factors to entice HTLV-1-infected 
cells and ATLSCs. These data also indicate the ovaries, an immune-privileged organ [68], may be a possible new niche for HTLV-1-infected cells or ATLSC refuges during the long latency period.

\section{MATERIALS AND METHODS}

\section{Mice}

All mouse experiments were approved by the Animal Care and Use Committee of the National Institute of Infectious Disease, Tokyo, Japan. C57BL/6-Ly5.1 mice congenic for the CD45 locus were purchased from Sankyo-Labo. Sl/Sld mice (WBB6F1/kit-Kitsl/Kitsl-d/ Slc) were purchased from SLC, Inc.

\section{Serial transplantation}

We used Ht48 cells, which are splenic ATL cells established from HBZ-Tg mice [28], for the first transplantation. ATL-like lymphoma and leukemia was first established in a female, 6-8-week-old C57BL/6-Ly5.1 mouse by an intraperitoneal injection of $3.5 \times 10^{7}$ frozen $\mathrm{Ht} 48$ cells. After 15 days, ATL-like lymphoma developed in the recipient mouse spleen, and the resulting $\mathrm{Ht} 48$ cells were capable of regenerating the original ATL-like lymphoma when further injected into new recipient mice. Using this transplantation system, $\mathrm{Ht} 48$ cells were serially passed as required.

\section{Cells preparation and flow cytometric analysis}

The spleens, livers, bone marrow (BM), thymuses, ovaries, inguinal and axillary lymph nodes (LNs), and ovaries were removed from Ht48 cell-recipient mice. Monoculear cells (MNCs) were isolated from each tissue using Lymphoprep ${ }^{\mathrm{TM}}$ (Axis-Shield), then stained with various antibodies (Supplemental Table 1) and with propidium iodide (50 ng; eBioscience) to distinguish live cells. For side population (SP) analysis, the MNCs were incubated $\left(1 \mathrm{~h} ; 37^{\circ} \mathrm{C}\right)$ with Hoechst33342 $(5 \mu \mathrm{g} / \mathrm{mL}$, Dojindo) with or without verapamil $(25 \mu \mathrm{g} / \mathrm{mL}$, Teva). Flowcytometric analyses and cell sorting with a J-SAN (Bay bioscience) were performed.

\section{Histological analysis}

Tissues were fixed with Bouin's solution (SigmaAldrich) and then dehydrated using graded series of ethanol and cleared with xylen. Tissues were embedded in paraffin and sliced into approximately $4-\mu \mathrm{m}$-thick sections. We performed Periodic Acid-Schiff (PAS) hematoxylin staining and immunohistochemistry as previously described 22. Primary antibodies (Supplemental Table 1) were detected with fluorescentlabeled secondary antibodies and nuclear DNA was detected with Hoechst33342. For single CD3 staining, a biotinylated secondary antibody was used with $\mathrm{ABC}$ solution (Vectastain) and colorized with diaminobenzidine (Merck Millipore). Sections were counterstained with hematoxylin. Microscopic analysis was performed with an Olympus BX53 and digital camera DP-73 with Cellsence capture and analyzing software.

\section{Cell culture}

We cultured each Ht48 cell fraction with IL-3, SCF, IL-6 (20 ng/mL each), Flt3-L, and IL-3 (4 ng/mL each) in RPMI 1640 with 20\% FBS for 6 days. All cytokines were obtained from Peprotech Inc (Supplemental Table 1).

\section{Microarray analysis}

Total RNA was amplified and labeled with cyanine 3 (Cy3) using an Agilent Low Input Quick Amp Labeling Kit (Agilent). cRNA quantity and $\mathrm{Cy} 3$ incorporation were determined using a Nanodrop ND-1000 spectrophotometer and an Agilent 2100 Bioanalyzer. For each hybridization, $600 \mathrm{ng}$ of Cy3-labeled cRNA were hybridized to an Agilent SurePrint G3 Mouse GE 8x60K Microarray (Design ID: 028005). Microarrays were scanned and the intensity values were quantified using Agilent feature extraction software, which performs background subtractions. Normalization was performed using Agilent GeneSpring (per chip: normalization to 75 percentile shift; per gene: normalization to the median of all samples). Data analysis and visualization including hierarchical clustering were carried out using TIBCO Spotfire (PerkinElmer).

\section{in situ hybridization}

To detect the target gene transcripts in $\mathrm{Ht} 48$ cells, we performed flow-cytometric analyses combined with in situ hybridization analyses by Primeflow RNA assays (eBioscience) according to their protocols. For section in situ hybridization, we used viewRNA ${ }^{\mathrm{TM}}$ (eBioscience) according to their protocols. Target probes were designed with Affymetrix (Supplemental Table 1).

\section{q-PCR analysis}

The primers for each target gene were designed with Primer 3 Plus (Supplemental Table 2). Total RNA (50 ng) was used for reverse transcription using SuperScriptIII First-Standard Synthesis System for RT-PCR (Thermo Fisher Scientific). Then, cDNA was amplified with SYBRPremix-ExTaqII (Takara-Bio) and analyzed by Applied 
Biosystems 7500 Fast Real-Time PCR System. The resulting data were analyzed using the comparative CT value for relative gene expression quantification against the housekeeping gene, $\beta$-Actin (mouse Actb).

\section{Data analysis}

All statistical analysis, including Student's $t$-test for gene expression analysis and Gehan-Breslow-Wilcoxon tests for survival curve analysis, were performed using GraphPad Prism (GraphPad Software) and Excel 2010 (Microsoft).

\section{ACKNOWLEDGMENTS}

We thank Dr. Yaushi Ami and Yuriko Suzaki for their technical advice and support for animal experiments, Yuko Sato, Kumiko Araki, and Mamiko Takai for their technical support for experiments, and Dr. Masumichi Saito, Msateru Hiyoshi, Kiyoko Nojima, and Kazu Ohkuma for their helpful scientific discussions.

\section{CONFLICTS OF INTEREST}

The authors declare that they have no competing financial interests.

\section{GRANT SUPPORT} (T.M).

This work was supported by JSPS KAKENHI Grant

\section{Editorial note}

This paper has been accepted based in part on peerreview conducted by another journal and the authors' response and revisions as well as expedited peer-review in Oncotarget.

\section{REFERENCES}

1. Uchiyama T, Yodoi J, Sagawa K, Takatsuki K and Uchino H. Adult T-cell leukemia: clinical and hematologic features of 16 cases. Blood. 1977; 50:481-492.

2. Gallo RC. The discovery of the first human retrovirus: HTLV-1 and HTLV-2. Retrovirology. 2005; 2:17.

3. Yamaguchi K. Human T-lymphotropic virus type I in Japan. Lancet (London, England). 1994; 343:213-216.

4. Arisawa K, Soda M, Endo S, Kurokawa K, Katamine S, Shimokawa I, Koba T, Takahashi T, Saito H, Doi H and Shirahama S. Evaluation of adult T-cell leukemia/ lymphoma incidence and its impact on non-Hodgkin lymphoma incidence in southwestern Japan. International journal of cancer. 2000; 85:319-324.
5. Tsukasaki K, Utsunomiya A, Fukuda H, Shibata T, Fukushima T, Takatsuka Y, Ikeda S, Masuda M, Nagoshi H, Ueda R, Tamura K, Sano M, Momita S, Yamaguchi K, Kawano F, Hanada S, et al. VCAP-AMP-VECP compared with biweekly CHOP for adult T-cell leukemia-lymphoma: Japan Clinical Oncology Group Study JCOG9801. Journal of clinical oncology. 2007; 25:5458-5464.

6. Fukushima T, Nomura S, Shimoyama M, Shibata T, Imaizumi Y, Moriuchi Y, Tomoyose T, Uozumi K, Kobayashi Y, Fukushima N, Utsunomiya A, Tara M, Nosaka K, Hidaka M, Uike N, Yoshida S, et al. Japan Clinical Oncology Group (JCOG) prognostic index and characterization of long-term survivors of aggressive adult T-cell leukaemia-lymphoma (JCOG0902A). British journal of haematology. 2014; 166:739-748.

7. Abdullah LN and Chow EK. Mechanisms of chemoresistance in cancer stem cells. Clinical and translational medicine. 2013; 2:3.

8. Bonnet D and Dick JE. Human acute myeloid leukemia is organized as a hierarchy that originates from a primitive hematopoietic cell. Nature medicine. 1997; 3:730-737.

9. Goardon N, Marchi E, Atzberger A, Quek L, Schuh A, Soneji S, Woll P, Mead A, Alford KA, Rout R, Chaudhury S, Gilkes A, Knapper S, Beldjord K, Begum S, Rose S, et al. Coexistence of LMPP-like and GMP-like leukemia stem cells in acute myeloid leukemia. Cancer cell. 2011; 19:138152.

10. Jamieson CH, Ailles LE, Dylla SJ, Muijtjens M, Jones C, Zehnder JL, Gotlib J, Li K, Manz MG, Keating A, Sawyers $\mathrm{CL}$ and Weissman IL. Granulocyte-macrophage progenitors as candidate leukemic stem cells in blast-crisis CML. The New England journal of medicine. 2004; 351:657-667.

11. Nilsson L, Astrand-Grundstrom I, Arvidsson I, Jacobsson B, Hellstrom-Lindberg E, Hast R and Jacobsen SE. Isolation and characterization of hematopoietic progenitor/stem cells in 5q-deleted myelodysplastic syndromes: evidence for involvement at the hematopoietic stem cell level. Blood. 2000; 96:2012-2021.

12. Woll PS, Kjallquist U, Chowdhury O, Doolittle H, Wedge DC, Thongjuea S, Erlandsson R, Ngara M, Anderson K, Deng Q, Mead AJ, Stenson L, Giustacchini A, Duarte S, Giannoulatou E, Taylor S, et al. Myelodysplastic syndromes are propagated by rare and distinct human cancer stem cells in vivo. Cancer cell. 2014; 25:794-808.

13. Tremblay CS and Curtis DJ. The clonal evolution of leukemic stem cells in T-cell acute lymphoblastic leukemia. Current opinion in hematology. 2014; 21:320-325.

14. Al-Hajj M, Wicha MS, Benito-Hernandez A, Morrison SJ and Clarke MF. Prospective identification of tumorigenic breast cancer cells. Proceedings of the National Academy of Sciences of the United States of America. 2003; 100:39833988.

15. Schatton T, Murphy GF, Frank NY, Yamaura K, WaagaGasser AM, Gasser M, Zhan Q, Jordan S, Duncan LM, Weishaupt C, Fuhlbrigge RC, Kupper TS, Sayegh MH 
and Frank MH. Identification of cells initiating human melanomas. Nature. 2008; 451:345-349.

16. Tian Y, Kobayashi S, Ohno N, Isobe M, Tsuda M, Zaike Y, Watanabe N, Tani K, Tojo A and Uchimaru K. Leukemic $\mathrm{T}$ cells are specifically enriched in a unique $\mathrm{CD} 3(\mathrm{dim})$ CD7(low) subpopulation of CD4(+) T cells in acute-type adult T-cell leukemia. Cancer science. 2011; 102:569-577.

17. Kobayashi S, Nakano K, Watanabe E, Ishigaki T, Ohno N, Yuji K, Oyaizu N, Asanuma S, Yamagishi M, Yamochi T, Watanabe N, Tojo A, Watanabe T and Uchimaru K. CADM1 expression and stepwise downregulation of CD7 are closely associated with clonal expansion of HTLV-Iinfected cells in adult T-cell leukemia/lymphoma. Clinical cancer research. 2014; 20:2851-2861.

18. Cook LB, Melamed A, Niederer H, Valganon M, Laydon D, Foroni L, Taylor GP, Matsuoka M and Bangham CR. The role of HTLV-1 clonality, proviral structure, and genomic integration site in adult T-cell leukemia/lymphoma. Blood. 2014; 123:3925-3931.

19. Zhou S, Schuetz JD, Bunting KD, Colapietro AM, Sampath J, Morris JJ, Lagutina I, Grosveld GC, Osawa M, Nakauchi $\mathrm{H}$ and Sorrentino BP. The ABC transporter Bcrp1/ABCG2 is expressed in a wide variety of stem cells and is a molecular determinant of the side-population phenotype. Nature medicine. 2001; 7:1028-1034.

20. Hirschmann-Jax C, Foster AE, Wulf GG, Nuchtern JG, Jax TW, Gobel U, Goodell MA and Brenner MK. A distinct "side population" of cells with high drug efflux capacity in human tumor cells. Proceedings of the National Academy of Sciences of the United States of America. 2004; 101:1422814233.

21. Hasegawa H, Sawa H, Lewis MJ, Orba Y, Sheehy N, Yamamoto Y, Ichinohe T, Tsunetsugu-Yokota Y, Katano H, Takahashi H, Matsuda J, Sata T, Kurata T, Nagashima $\mathrm{K}$ and Hall WW. Thymus-derived leukemia-lymphoma in mice transgenic for the Tax gene of human T-lymphotropic virus type I. Nature medicine. 2006; 12:466-472.

22. Yamazaki J, Mizukami T, Takizawa K, Kuramitsu M, Momose H, Masumi A, Ami Y, Hasegawa H, Hall WW, Tsujimoto H, Hamaguchi I and Yamaguchi K. Identification of cancer stem cells in a Tax-transgenic (Tax-Tg) mouse model of adult T-cell leukemia/lymphoma. Blood. 2009; 114:2709-2720.

23. El Hajj H, El-Sabban M, Hasegawa H, Zaatari G, Ablain J, Saab ST, Janin A, Mahfouz R, Nasr R, Kfoury Y, Nicot C, Hermine O, Hall W, de The H and Bazarbachi A. Therapyinduced selective loss of leukemia-initiating activity in murine adult $\mathrm{T}$ cell leukemia. The Journal of experimental medicine. 2010; 207:2785-2792.

24. Nagai Y, Kawahara M, Hishizawa M, Shimazu Y, Sugino N, Fujii S, Kadowaki N and Takaori-Kondo A. T memory stem cells are the hierarchical apex of adult T-cell leukemia. Blood. 2015; 125:3527-3535.

25. Takeda S, Maeda M, Morikawa S, Taniguchi Y, Yasunaga
J, Nosaka K, Tanaka Y and Matsuoka M. Genetic and epigenetic inactivation of tax gene in adult T-cell leukemia cells. International journal of cancer. 2004; 109:559-567.

26. Arnold J, Zimmerman B, Li M, Lairmore MD and Green PL. Human T-cell leukemia virus type-1 antisense-encoded gene, Hbz, promotes T-lymphocyte proliferation. Blood. 2008; 112:3788-3797.

27. Satou Y, Yasunaga J, Zhao T, Yoshida M, Miyazato P, Takai K, Shimizu K, Ohshima K, Green PL, Ohkura N, Yamaguchi T, Ono M, Sakaguchi S and Matsuoka M. HTLV-1 bZIP factor induces T-cell lymphoma and systemic inflammation in vivo. PLoS pathogens. 2011; 7:e1001274.

28. Sugata K, Yasunaga J, Mitobe Y, Miura M, Miyazato P, Kohara M and Matsuoka M. Protective effect of cytotoxic T lymphocytes targeting HTLV-1 bZIP factor. Blood. 2015; 126:1095-1105.

29. Lemoine FJ, Wycuff DR and Marriott SJ. Transcriptional activity of HTLV-I Tax influences the expression of marker genes associated with cellular transformation. Disease markers. 2001; 17:129-137.

30. Tsukasaki K, Tanosaki S, DeVos S, Hofmann WK, Wachsman W, Gombart AF, Krebs J, Jauch A, Bartram CR, Nagai K, Tomonaga M, Said JW and Koeffler HP. Identifying progression-associated genes in adult T-cell leukemia/lymphoma by using oligonucleotide microarrays. International journal of cancer. 2004; 109:875-881.

31. Yasunaga J, Taniguchi Y, Nosaka K, Yoshida M, Satou Y, Sakai T, Mitsuya H and Matsuoka M. Identification of aberrantly methylated genes in association with adult $\mathrm{T}$-cell leukemia. Cancer research. 2004; 64:6002-6009.

32. Yasunaga J and Matsuoka M. Human T-cell leukemia virus type I induces adult T-cell leukemia: from clinical aspects to molecular mechanisms. Cancer control. 2007; 14:133140.

33. Pise-Masison CA, Radonovich M, Dohoney K, Morris JC, O’Mahony D, Lee MJ, Trepel J, Waldmann TA, Janik JE and Brady JN. Gene expression profiling of ATL patients: compilation of disease-related genes and evidence for TCF4 involvement in BIRC5 gene expression and cell viability. Blood. 2009; 113:4016-4026.

34. Kataoka K, Nagata Y, Kitanaka A, Shiraishi Y, Shimamura T, Yasunaga J, Totoki Y, Chiba K, Sato-Otsubo A, Nagae G, Ishii R, Muto S, Kotani S, Watatani Y, Takeda J, Sanada $\mathrm{M}$, et al. Integrated molecular analysis of adult $\mathrm{T}$ cell leukemia/lymphoma. Nature genetics. 2015; 47:1304-1315.

35. McCulloch EA, Siminovitch L, Till JE, Russell ES and Bernstein SE. The cellular basis of the genetically determined hemopoietic defect in anemic mice of genotype Sl-Sld. Blood. 1965; 26:399-410.

36. Bazarbachi A, Ghez D, Lepelletier Y, Nasr R, de The H, El-Sabban ME and Hermine O. New therapeutic approaches for adult T-cell leukaemia. The Lancet Oncology. 2004; 5:664-672. 
37. Hamburger AW and Salmon SE. Primary bioassay of human tumor stem cells. Science (New York, NY). 1977; 197:461-463.

38. Magee JA, Piskounova E and Morrison SJ. Cancer stem cells: impact, heterogeneity, and uncertainty. Cancer cell. 2012; 21:283-296.

39. Fukuda Y, Lian S and Schuetz JD. Leukemia and ABC transporters. Advances in cancer research. 2015; 125:171196.

40. Hivin P, Basbous J, Raymond F, Henaff D, Arpin-Andre C, Robert-Hebmann V, Barbeau B and Mesnard JM. The HBZ-SP1 isoform of human T-cell leukemia virus type I represses JunB activity by sequestration into nuclear bodies. Retrovirology. 2007; 4:14.

41. Thebault S, Basbous J, Hivin P, Devaux C and Mesnard JM. HBZ interacts with JunD and stimulates its transcriptional activity. FEBS letters. 2004; 562:165-170.

42. Fujii M, Niki T, Mori T, Matsuda T, Matsui M, Nomura N and Seiki M. HTLV-1 Tax induces expression of various immediate early serum responsive genes. Oncogene. 1991; 6:1023-1029.

43. Mori N, Fujii M, Iwai K, Ikeda S, Yamasaki Y, Hata T, Yamada Y, Tanaka Y, Tomonaga M and Yamamoto N. Constitutive activation of transcription factor AP-1 in primary adult T-cell leukemia cells. Blood. 2000; 95:39153921.

44. Misawa A, Katayama R, Koike S, Tomida A, Watanabe $\mathrm{T}$ and Fujita N. AP-1-Dependent miR-21 expression contributes to chemoresistance in cancer stem cell-like SP cells. Oncology research. 2010; 19:23-33.

45. Passegue E, Jochum W, Schorpp-Kistner M, MohleSteinlein U and Wagner EF. Chronic myeloid leukemia with increased granulocyte progenitors in mice lacking junB expression in the myeloid lineage. Cell. 2001; 104:2132.

46. Steidl U, Rosenbauer F, Verhaak RG, Gu X, Ebralidze A, Otu HH, Klippel S, Steidl C, Bruns I, Costa DB, Wagner K, Aivado M, Kobbe G, Valk PJ, Passegue E, Libermann TA, et al. Essential role of Jun family transcription factors in PU.1 knockdown-induced leukemic stem cells. Nature genetics. 2006; 38:1269-1277.

47. Passegue E, Wagner EF and Weissman IL. JunB deficiency leads to a myeloproliferative disorder arising from hematopoietic stem cells. Cell. 2004; 119:431-443.

48. Santaguida M, Schepers K, King B, Sabnis AJ, Forsberg EC, Attema JL, Braun BS and Passegue E. JunB protects against myeloid malignancies by limiting hematopoietic stem cell proliferation and differentiation without affecting self-renewal. Cancer cell. 2009; 15:341-352.

49. Lennartsson J and Ronnstrand L. Stem cell factor receptor/c-Kit: from basic science to clinical implications. Physiological reviews. 2012; 92:1619-1649.

50. Heinrich MC, Blanke CD, Druker BJ and Corless CL.
Inhibition of KIT tyrosine kinase activity: a novel molecular approach to the treatment of KIT-positive malignancies. Journal of clinical oncology. 2002; 20:1692-1703.

51. Broudy VC, Smith FO, Lin N, Zsebo KM, Egrie J and Bernstein ID. Blasts from patients with acute myelogenous leukemia express functional receptors for stem cell factor. Blood. 1992; 80:60-67.

52. Turtle CJ, Swanson HM, Fujii N, Estey EH and Riddell SR. A distinct subset of self-renewing human memory CD8+ T cells survives cytotoxic chemotherapy. Immunity. 2009; 31:834-844.

53. Godfrey DI, Kennedy J, Suda T and Zlotnik A. A developmental pathway involving four phenotypically and functionally distinct subsets of CD3-CD4-CD8- triplenegative adult mouse thymocytes defined by CD44 and CD25 expression. Journal of immunology (Baltimore, Md : 1950). 1993; 150:4244-4252.

54. Sambandam A, Maillard I, Zediak VP, Xu L, Gerstein RM, Aster JC, Pear WS and Bhandoola A. Notch signaling controls the generation and differentiation of early $\mathrm{T}$ lineage progenitors. Nature immunology. 2005; 6:663-670.

55. Allen A, Sireci A, Colovai A, Pinkney K, Sulis M, Bhagat G and Alobeid B. Early T-cell precursor leukemia/lymphoma in adults and children. Leukemia research. 2013; 37:10271034.

56. Marodon G, Warren D, Filomio MC and Posnett DN. Productive infection of double-negative T cells with HIV in vivo. Proceedings of the National Academy of Sciences of the United States of America. 1999; 96:11958-11963.

57. Margolick JB, Carey V, Munoz A, Polk BF, Giorgi JV, Bauer KD, Kaslow R and Rinaldo C. Development of antibodies to HIV-1 is associated with an increase in circulating CD3+CD4-CD8- lymphocytes. Clinical immunology and immunopathology. 1989; 51:348-361.

58. Cheney KM, Kumar R, Purins A, Mundy L, Ferguson W, Shaw D, Burrell CJ and Li P. HIV type 1 persistence in CD4- /CD8- double negative $\mathrm{T}$ cells from patients on antiretroviral therapy. AIDS research and human retroviruses. 2006; 22:66-75.

59. Hillhouse EE and Lesage S. A comprehensive review of the phenotype and function of antigen-specific immunoregulatory double negative $\mathrm{T}$ cells. Journal of autoimmunity. 2013; 40:58-65.

60. Ma S, Shi Y, Pang Y, Dong F, Cheng H, Hao S, Xu J, Zhu $\mathrm{X}$, Yuan W, Cheng T and Zheng G. Notch1-induced T cell leukemia can be potentiated by microenvironmental cues in the spleen. Journal of hematology \& oncology. 2014; 7:71.

61. Ferry JA and Young RH. Malignant lymphoma, pseudolymphoma, and hematopoietic disorders of the female genital tract. Pathology annual. 1991; 26 Pt 1:227263.

62. Engels EA. Infectious agents as causes of non-Hodgkin lymphoma. Cancer epidemiology, biomarkers \& prevention. 2007; 16:401-404. 
63. Nakamura S, Kato M, Ichimura K, Yatabe Y, Kagami Y, Suzuki R, Taji H, Kondo E, Asakura S, Kojima M, Murakami S, Yamao K, Tsuzuki T, Adachi GK, Miwa A and Yoshidai T. Peripheral T/natural killer-cell lymphoma involving the female genital tract: a clinicopathologic study of 5 cases. International journal of hematology. 2001; 73:108-114.

64. Dewan MZ, Takamatsu N, Hidaka T, Hatakeyama K, Nakahata S, Fujisawa J, Katano H, Yamamoto N and Morishita K. Critical role for TSLC1 expression in the growth and organ infiltration of adult T-cell leukemia cells in vivo. Journal of virology. 2008; 82:11958-11963.

65. Iwai T, Fujii S, Nanbu Y, Nonogaki H, Konishi I, Mori T, Masutani H and Yodoi J. Expression of adult T-cell leukaemia-derived factor, a human thioredoxin homologue, in the human ovary throughout the menstrual cycle. Virchows Archiv A, Pathological anatomy and histopathology. 1992; 420:213-217.
66. Tagaya Y, Maeda Y, Mitsui A, Kondo N, Matsui H, Hamuro J, Brown N, Arai K, Yokota T, Wakasugi H and et al. ATL-derived factor (ADF), an IL-2 receptor/Tac inducer homologous to thioredoxin; possible involvement of dithiol-reduction in the IL-2 receptor induction. The EMBO journal. 1989; 8:757-764.

67. Abir R, Fisch B, Jin S, Barnnet M, Kessler-Icekson G and Ao A. Expression of stem cell factor and its receptor in human fetal and adult ovaries. Fertility and sterility. 2004; 82 Suppl 3:1235-1243.

68. Givens MD and Marley MS. Immunology of chronic BVDV infections. Biologicals. 2013; 41:26-30. 